\title{
THREE-PHASE PACKED BED REACTOR WITH AN EVAPORATING SOLVENT-II. MODELLING OF THE REACTOR
}

\author{
K. B. VAN GELDER, P. C. BORMAN, R. E. WEENINK and K. R. WESTERTERP ${ }^{\dagger}$ \\ Department of Chemical Engincering, Twente University of Technology, PO Box 217, 7500 AE Enschede, \\ Netherlands
}

(Received 22 December 1988; accepted 26 October 1989)

\begin{abstract}
In this paper two models are presented for a three-phase catalytic packed bed reactor in which an evaporating solvent is used to absorb and remove most of the reaction heat. A plug flow model and a model comprising mass and heat dispersion in the reactor are discussed. The results of both models are compared to each other and to experimental data obtained in a miniplant on the hydrogenation of $2,4,6-$ trinitrotoluene to triaminotoluene described in Part I. The influence of reactor pressure, feed temperature and the molar ratio of hydrogen to the reactant in the feed are discussed. It is concluded that both models can well describe the influence of the operating variables on the reactor behaviour and that a large part of the reaction heat can be removed by evaporation of the solvent. From a comparison with the experimental results it is concluded that the dispersion model can well describe the experimental data for a fresh catalyst. The agreement between the model and the experimental data for a deactivated catalyst is not good. As long as no quantitative description of the local deactivation in the packed bed is available, any model will fail to predict local concentrations in the reactor. Despite this drawback recommendations can be given how to use this reactor type to optimize the selectivity in producing an intermediate product.
\end{abstract}

\section{INTRODUCTION}

The rising costs of adhering to more and stricter limitations on environmental pollution levels have increased the demand in the chemical industry for cleaner processes. In the fine chemicals industry the Béchamps process, used for hydrogenation of intermediate products, yields high quantities of waste fluids containing metal and halogen compounds. A "clean" alternative is the catalytic hydrogenation of the intermediates.

In our laboratory we are investigating catalytic hydrogenation reactions in three-phase systems. Our purpose is to develop a reactor that is suitable for use in the fine chemicals industry. The reactions that we are interested in are conducted in the liquid phase and are highly exothermic and complex reactions. We are aiming at high yields for intermediate products. This means that we must have good control over the temperature in the reactor. In our miniplant we have chosen to use an evaporating solvent to absorb and remove most of the reaction heat.

Hydrogenation processes are generally very exothermic. This can cause problems in the fine chemicals industry as generally there are very strict limits to the maximum temperature in the reactor. Using a system with an evaporating solvent provides good control over this maximum temperature. The solvent will evaporate until the gas phase is saturated at the prevailing temperature. The maximum temperature in the reactor is the boiling point of the solvent at the reactor pressure. However, this boiling point will never be reached because the evaporation rate rises

Author to whom correspondence should be addressed. exponentially with temperature and will reach infinity at the boiling point. This was shown by Westerterp and Crombeen (1983).

In Part I we reported on experimental results obtained in our miniplant on the hydrogenation of $2,4,6$ trinitrotoluene (TNT) in methanol. To our knowledge no extensive theoretical or experimental study has been done on systems in which the evaporation of a solvent is used to transport most of the reaction heat. In this paper we consider the modelling of such a system and we will compare the model simulations to some of our experimental data.

In this paper we present two models for a threephase catalytic reactor with an evaporating solvent. Firstly, we present a plug flow model. This type of model can be solved by standard mathematical techniques on most personal computers. Although the model itself is probably too simple for our type of reactor it is very well suited to study its behaviour and to identify the main operating parameters. Secondly, we present a dispersion model in which mass and heat dispersion are incorporated. This type of model generally needs a mainframe computer due to the larger mathematical and storage capacities needed to solve the boundary type differential equations but will be more in accordance with reality.

\section{DESCRIPTION OF THE REACTION SYSTEM}

The formulation of the model equations is closely related to the properties of the reaction system we wish to describe. We will therefore give a concise description of the reactor and reaction system, i.e. the combination of the reactor type, flow pattern, physical 
and chemical properties of the phases and reactants, reaction kinetics, etc.

For a detailed description of the reactor we refer the reader to van Gelder (1988). A schematic drawing of the reactor we wish to model is given in Fig. 1. The model reaction we wish to study is relatively slow and we have chosen to use a cocurrent upflow packed bed reactor. Cocurrent upflow operation results in a higher liquid hold-up than either cocurrent downflow or countercurrent flow. The reactor is operated in the bubble flow regime. A Pd on alumina shell catalyst with $0.08 \mathrm{wt} \%$ of $\mathrm{Pd}$ on $4.2 \times 4.2 \mathrm{~mm}$ cylindrical alumina pellets was used. The gas and the liquid enter the catalyst bed through a small mixing chamber, designed to enhance the gas-liquid contact and to provide a good distribution of the phases over the bed.

The hydrogenation of TNT in methanol was chosen as a model reaction. This reaction is very exothermic with a heat effect of $-1850 \mathrm{~kJ} / \mathrm{mol}$ of TNT for complete conversion to triaminotoluene (TAT) and is relatively slow. At average reactor conditions of $T_{\text {feed }}=55^{\circ} \mathrm{C}$ and $P_{\mathrm{R}}=0.4 \mathrm{MPa}$ a residence time of approximately $15 \mathrm{~min}$ is needed for complete conversion to TAT.

The models we develop have to be suitable for any cocurrent three-phase reactor in which evaporation of the solvent occurs.

\section{MODELLING THE EVAPORATION}

There are two possibilities to describe the evaporation of the solvent. Firstly, we can assume that at each axial coordinate $Z$ in the reactor the gas phase is saturated with the solvent at the prevailing temperature. Secondly, we can describe the evaporation by using a mass transfer equation. The vapour pressure of the solvent at the gas-liquid interface is then assumed to be equal to the saturated vapour pressure.

Describing the evaporation by using a mass transfer equation leads to a simpler model, because this gives us a quantitative description of the amount of solvent that evaporates: the product of the concentration difference, the interfacial area and the mass transfer coefficient. This quantity can be substituted in other mass balances and in the enthalpy balance. If we assume that the gas phase is saturated with the solvent there is no term that quantitatively describes the amount of solvent evaporating and the model equations become strongly coupled and more difficult to solve.

Evaluation of a simplified plug flow model in which the evaporation was modelled using the mass transfer

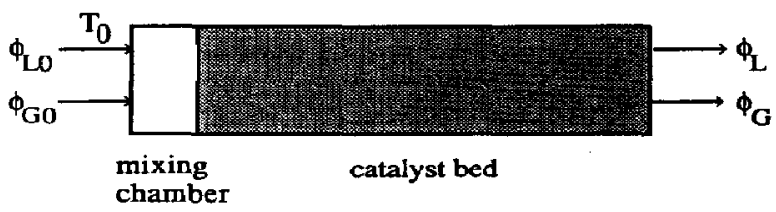

Fig. 1. Schematic drawing of the reactor system. equation and conservative estimates for the gasliquid interfacial area and the mass transfer coefficient showed that the gas phase is always practically saturated with the solvent.

For the plug flow model we have therefore chosen to assume that the gas phase is saturated with the solvent at each axial position $Z$ in the reactor. However, for the dispersion model we have decided to describe the evaporation by using a mass transfer equation. This was done to simplify the dispersion equations and must only be seen as a mathematical manipulation to make the model equations more easily accessible for numerical treatment.

\section{REACTION KINETICS}

The hydrogenation of 2,4,6-trinitrotoluene was chosen as a model reaction, because it is a very exothermic, complex reaction. The kinetics of this reaction with a $\mathbf{P d}$ on carbon catalyst in a slurry reactor have been extensively studied in our laboratory [see Janssen et al. (1987)]. The reaction scheme was found to be a complex network of parallel and consecutive reactions. To describe the consumption of hydrogen in this reaction network a lumped system of three consecutive reaction steps has been used:

$$
\begin{aligned}
& \mathrm{TNT}+2 \mathrm{H}_{2} \stackrel{r_{1}}{\rightarrow} \text { DNHAT }+\mathrm{H}_{2} \mathrm{O} \\
& \mathrm{DNHAT}+4 \mathrm{H}_{2} \stackrel{r_{2}}{\rightarrow} \text { DANT }+4 \mathrm{H}_{2} \mathrm{O} \\
& \text { DANT }+3 \mathrm{H}_{2} \stackrel{r_{3}}{\rightarrow} \text { TAT }+2 \mathrm{H}_{2} \mathrm{O}
\end{aligned}
$$

in which:

$$
\begin{aligned}
\text { DNHAT } & =\text { dinitrohydroxylaminetoluene } \\
\text { DANT } & =\text { diaminonitrotoluene. }
\end{aligned}
$$

The reactions were found to be of the LangmuirHinshelwood type with different active sites for the nitro components and the hydrogen. The equation for the reaction rate was formulated as:

$$
r_{i}=k_{i} \frac{K_{i} C_{i}}{\left(1+\sum_{j=1}^{3} K_{j} C_{j}\right)\left(1+K_{\mathrm{H}} \frac{\boldsymbol{P}_{\mathrm{H}}}{R T}\right)^{\frac{P_{\mathrm{H}}}{R T}}} \mathrm{~m}_{\mathrm{cat}}
$$

Janssen et al. based the reaction rate expression on the unit of mass of catalyst. We used a different catalyst, $P d$ on cylindrical alumina pellets instead of on a fine active carbon powder. The basic kinetic data as obtained for Pd on carbon therefore have to be translated to this different carrier and to this end we introduce an efficiency factor $\eta$. The best value for this efficiency factor has to be found by trial and error, by comparing the model simulations and the experiments. The term $m_{\mathrm{cat}}$ will be replaced by $\eta_{0} \rho_{\mathrm{cat}}$ in which $\rho_{\text {cat }}$ is the mass of catalyst per $\mathrm{m}^{3}$ reactor volume and $\eta_{0}$ is a scaling factor based on the differ- 
ence in the available surface area between the carbon powder used during the kinetics experiments and the shell catalyst used in our packed bubble column. A basic assumption that we make is that the reaction kinetics for a Pd catalyst are the same irrespective of the catalyst carrier.

The conversion $\zeta$ for this system of multiple reactions is based on the hydrogen consumption and defined as the amount of hydrogen consumed over the maximum hydrogen consumption for complete conversion of all TNT to TAT.

Using the reaction rate equations as given demands for extreme caution as these were obtained from fitting the experimental data to the conversion profiles calculated from the measured hydrogen consumption! Results obtained in our laboratory indicate that these equations can be used with good results to predict heat effects and overall conversion in a CSTR [see Janssen et al. (1987)]. However, the equations cannot be used to predict the liquid phase composition. In this paper we nevertheless use the equations to calculate the liquid phase composition in order to illustrate our models. We must bear in mind that this is a hypothetical situation and that we can only compare the calculated conversion and temperature profiles to our experimental results. In order to prevent misinterpretation of our model illustrations we rename the components and use the scheme as follows:

$$
\begin{aligned}
& \mathrm{A}+2 \mathrm{H}_{2} \stackrel{\mathrm{r}_{1}}{\rightarrow} \mathrm{B}+\mathrm{H}_{2} \mathrm{O} \\
& \mathrm{B}+4 \mathrm{H}_{2} \stackrel{\mathrm{r}_{2}}{\rightarrow} \mathrm{C}+4 \mathrm{H}_{2} \mathrm{O} \\
& \mathrm{C}+3 \mathrm{H}_{2} \stackrel{r_{3}}{\rightarrow} \mathrm{P}+2 \mathrm{H}_{2} \mathrm{O} .
\end{aligned}
$$

\section{THE PLUG FLOW MODEL}

\subsection{Assumptions}

The derived model equations are based on the following assumptions:

1. Both phases are in plug flow.

2. The reactor is adiabatic and isobaric.

3. The gas and the liquid enter the mixing chamber at the same temperature $T_{0}$.

4. The gas phase is saturated with the solvent when it enters the catalyst bed. This assumption is based on the presence of the gas-liquid mixing chamber at the entrance of the reactor.

5. In the reactor the gas phase is saturated with the solvent (at any $h$ ).

6. There are no mass transfer limitations.

7. The temperature in all three phases is uniform in a plane perpendicular to the direction of flow.

8. There are no concentration profiles in the radial direction.

9. There is no heat conduction in the axial direction.

10. The available catalyst area is fully wetted and utilized.

11. The nitro compounds are not volatile.
12. Except for vapour-liquid equilibrium the liquid phase behaves ideally.

13. The gas phase is ideal.

14. For the calculation of the vapour pressure the liquid is assumed to consist of methanol and water only.

15. The contribution of the nitro compounds to the molar weight and the specific heat of the liquid phase can be neglected.

On these assumptions the relevant balance equations can now be formulated.

\subsection{Model equations for the mixer}

The mixer is given in Fig. 2. The feed conditions to the mixer are indicated by an index 0 ; the conditions in the mixer are indicated by an index $(h=0)$ as these are the conditions at the entrance of the catalyst bed at $h=0$. The mixer is described by the following equations:

A mole balance for hydrogen in the gas phase

$$
\phi_{\mathrm{GO}}-y_{\mathbf{H}(h=0)} \phi_{\mathrm{G}(h=0)}=0
$$

From the detinition of mole fractions

$$
\sum y_{i}=1
$$

Overall balance for the gas and liquid flows over the mixer

$$
\left(\phi_{\mathrm{LO}}+\phi_{\mathrm{GO}}\right)-\left(\phi_{\mathrm{L}(h-0)}+\phi_{\mathrm{G}(h=0)}\right)=0
$$

Enthalpy balance

$$
\begin{gathered}
C_{\mathrm{PG}(h=0)} M_{\mathrm{G}(h=0)} \phi_{\mathrm{G}(h=0)}\left(T_{(h=0)}-T_{0}\right)+ \\
C_{\mathrm{pL}(h=0)} M_{\mathrm{L}(h=0)} \phi_{\mathrm{L}(h=0)}\left(T_{(h=0)}-T_{0}\right)+ \\
\Delta H_{\mathrm{eV}, \text { sol }} y_{\mathrm{sol}(h=0)} \phi_{\mathrm{G}(h=0)}=0
\end{gathered}
$$

The mole fraction solvent in the gas phase is calculated using:

$$
y_{\mathrm{sol}(h=0)}=\frac{P_{\mathrm{sol} 1}^{\mathrm{u}}\left(T_{(h=0)}\right)}{P} .
$$

Equations (2) (6) can be solved by rewriting them as follows and iterating over the temperature in the

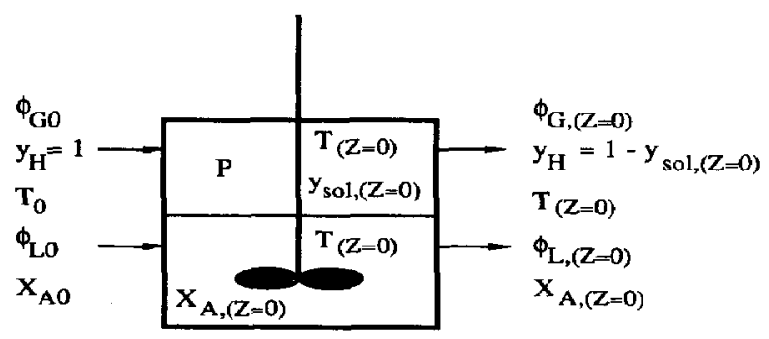

Fig. 2. Molar balances over the gas and liquid phases in the mixer. The conditions in the mixer are the initial conditions at $Z=0$ for the plug flow model. 
mixer $T_{(h=0)}$ :

$$
\begin{aligned}
& y_{\mathbf{H}(h=0)}=1-y_{\mathrm{sol}(h=0)} \\
& \phi_{\mathrm{G}(h=0)}=\phi_{\mathrm{GO}} / y_{\mathrm{H}(h=0)} \\
& \phi_{\mathrm{L}(h=0)}=\phi_{\mathrm{LO}}-y_{\mathrm{sol}(h=0)} \phi_{\mathrm{G}(h=0)}
\end{aligned}
$$$$
T_{(h=0)}=T_{0}-\frac{\Delta H_{\mathrm{ev}, \mathrm{sol}} y_{\mathrm{sol}(h=0)} \phi_{\mathrm{G}(h=0)}}{\left(C_{\mathrm{pG}(h=0)} M_{\mathrm{G}(h=0)} \phi_{\mathrm{G}(h=0)}+C_{\mathrm{pL}(h=0)} M_{\mathrm{L}(h=0)} \phi_{\mathrm{L}(h=0)}\right)}
$$

For the solvent in the gas phase

$$
y_{\text {sol }}\left(\frac{\mathrm{d} \phi_{\mathrm{G}}}{\mathrm{d} h}\right)+\phi_{\mathrm{G}}\left(\frac{\mathrm{d} y_{\mathrm{sol}}}{\mathrm{d} h}\right)-\phi_{\mathrm{ir}}^{\mathrm{sol}}=0
$$

\subsection{The model equations for the reactor}

With our model equations we wish to describe the following variables as a function of the axial position in the catalyst bed:

the liquid flow rate, $\phi_{\mathbf{L}}$

the composition of the liquid phase, $x_{A}, x_{B}, x_{C}, x_{P}$,

$x_{\mathbf{w}}, x_{\mathrm{sol}}$

the gas flow rate, $\phi_{\mathbf{G}}$

the composition of the gas phase, $y_{\text {sol }}, y_{W}, y_{H}$

the temperature, $T$.

The model equations are derived from differential mole balances over a small volume element of the reactor (see Fig. 3):

For reactants and products

$$
\begin{gathered}
x_{i}\left(\frac{\mathrm{d} \phi_{\mathrm{L}}}{\mathrm{d} h}\right)+\phi_{\mathrm{L}}\left(\frac{\mathrm{d} x_{i}}{\mathrm{~d} h}\right)-\eta r_{\mathrm{prod}, i}=0 \\
\text { for } i=\mathrm{A}, \mathrm{B}, \mathrm{C}
\end{gathered}
$$

A mole balance over the reactants

$$
\phi_{\mathrm{L} 0} x_{\mathrm{A}, 0}-\phi_{\mathrm{L}}\left(x_{\mathrm{A}}+x_{\mathrm{B}}+x_{\mathrm{C}}+x_{\mathrm{P}}\right)=0
$$

For water in the liquid phase

$$
x_{\mathbf{w}}\left(\frac{\mathrm{d} \phi_{\mathrm{L}}}{\mathrm{d} h}\right)+\phi_{\mathrm{L}}\left(\frac{\mathrm{d} x_{\mathrm{w}}}{\mathrm{d} h}\right)-\eta r_{\mathrm{prod}, \mathrm{w}}+\phi_{\mathrm{tr}}^{\mathbf{w}}=0
$$

For water in the gas phase

$$
y_{\mathrm{W}}\left(\frac{\mathrm{d} \phi_{\mathrm{G}}}{\mathrm{d} h}\right)+\phi_{\mathrm{G}}\left(\frac{\mathrm{d} y_{\mathrm{W}}}{\mathrm{d} h}\right)-\phi_{\mathrm{tr}}^{\mathbf{w}}=0
$$

For the solvent in the liquid phase

$$
x_{\mathrm{sol}}\left(\frac{\mathrm{d} \phi_{\mathrm{L}}}{\mathrm{d} h}\right)+\phi_{\mathrm{I}}\left(\frac{\mathrm{d} x_{\mathrm{sol}}}{\mathrm{d} h}\right)+\phi_{\mathrm{ir}}^{\mathrm{sol}}=0
$$

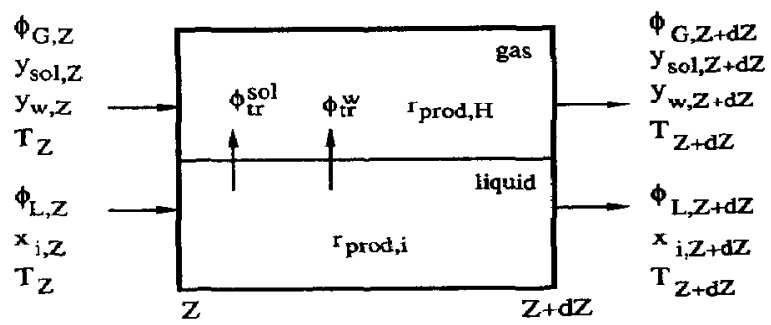

Fig. 3. Molar balances for the plug flow model over a small volume element in the catalyst bed.
For hydrogen in the gas phase

$$
y_{\mathrm{H}}\left(\frac{\mathrm{d} \phi_{\mathrm{G}}}{\mathrm{d} h}\right)+\phi_{\mathrm{G}}\left(\frac{\mathrm{d} y_{\mathrm{H}}}{\mathrm{d} h}\right)-\eta r_{\text {prod, } \mathbf{H}}=0
$$

Enthalpy balance over the whole differential volume

$$
\begin{aligned}
& \sum_{j=1}^{3} \eta r_{i}\left(-\Delta H_{r i}\right)+\left(C_{\mathrm{pG}} M_{\mathrm{G}} \phi_{\mathrm{G}}+C_{\mathrm{pL}} M_{\mathrm{L}} \phi_{\mathrm{L}}\right)\left(\frac{\mathrm{d} T}{\mathrm{~d} h}\right) \\
&-\Delta H_{\mathrm{ev}, \mathbf{s o l}} \phi_{\mathrm{tr}}^{\mathrm{sol}}-\Delta H_{\mathrm{ev}, \mathrm{w}} \phi_{\mathrm{tr}}^{\mathbf{w}}=0
\end{aligned}
$$

The mole fraction of solvent in the gas phase

$$
y_{\mathrm{sol}}=\gamma_{\mathrm{sol}} x_{\mathrm{sol}}\left(\frac{P_{\mathrm{sol}}^{\mathrm{o}}(T)}{P}\right)
$$

The mole fraction of water in the gas phase

$$
y_{\mathrm{w}}=\gamma_{\mathrm{w}} \dot{x}_{\mathrm{w}}\left(\frac{P_{\mathrm{w}}^{\mathrm{o}}(T)}{P}\right)
$$

From the definition of mole fractions

$$
\sum x_{i}=1 \text { and } \sum y_{i}=1
$$

In these equations $\eta r_{\text {prod }, i}$ is the amount of component $i$ produced per $\mathrm{m}^{3}$ reactor volume per unit of time and $\eta r_{i}$ is the reaction rate with which component $i$ is transformed into component $i+1$, i.e. $\eta r_{\mathrm{prod}, \mathrm{B}}=\eta\left(r_{\mathrm{A}}\right.$ $\left.-r_{\mathbf{B}}\right)$.

The transfer terms $\phi_{\mathrm{tr}}^{i}$ are defined as the number of moles of component $i$ transferred from the liquid to the gas phase per $\mathrm{m}^{3}$ reactor volume per unit of time.

The molar weight of the gas and the liquid phase are assumed to be constant over the differential element and are calculated according to: $M=\Sigma x_{i} M_{i}$. The specific heat of the gas and the liquid phase are assumed constant over the differential element and are calculated according to: $C_{\mathrm{p}}=\sum x_{i} C_{\mathrm{p} i} \cdot C_{\mathrm{p} i}$ is assumed to be independent of temperature and pressure.

\subsection{Dimensionless equations and groups}

These equations can be made dimensionless by defining the following dimensionless variables: Dimensionless gas and liquid flow rates

$$
\begin{aligned}
\Phi_{G} & =\phi_{G} / \phi_{G O} \\
\Phi_{L} & =\phi_{L} / \phi_{L O}
\end{aligned}
$$

Dimensionless axial coordinate

$$
Z=h / L
$$


Dimensionless production and reaction rates

$$
\begin{aligned}
R_{\text {prod }, i} & =r_{\text {prod }, i} /\left(\rho_{\mathrm{cat}} k_{1, \mathrm{~s}}\right) \\
\boldsymbol{R}_{\boldsymbol{i}} & =\boldsymbol{r}_{i} /\left(\rho_{\mathrm{cat}} k_{1, \mathrm{~s}}\right)
\end{aligned}
$$

where $k_{1, s}$ is the reaction rate constant of the reaction $\mathrm{A} \rightarrow \mathrm{B}$ at an arbitrary reference temperature $T_{\mathrm{S}}$.

Dimensionless mole fraction of reactants

$$
X_{i}=x_{i} / x_{\mathrm{A}, 0}
$$

Dimensionless specific heat of the gas and liquid phases

$$
\begin{aligned}
& C_{\mathrm{pG}}=C_{\mathrm{pG}} / C_{\mathrm{pG}, 0} \\
& C_{\mathrm{pL}}=C_{\mathrm{pL}} / C_{\mathrm{pL}, 0}
\end{aligned}
$$

Dimensionless molar weights of the gas and the liquid phases

$$
\begin{aligned}
M_{\mathrm{G}} & =M_{\mathrm{G}} / M_{\mathrm{G}, 0} \\
M_{\mathrm{L}} & =M_{\mathrm{L}} / M_{\mathrm{L}, 0}
\end{aligned}
$$

Dimensionless temperature

$$
\theta=-\left(\frac{E_{1}}{R T_{\mathrm{S}}}\right)\left(1-\frac{T}{T_{\mathrm{s}}}\right)
$$

The dimensionless temperature $\theta$ is defined in accordance with the definition used by Westerterp and Crombeen (1983). In this definition $T_{\mathrm{s}}$ is an arbitrary reference temperature. If we define a parameter $\Psi$ as:

$$
\Psi=R T_{\mathrm{S}} / E_{1}
$$

we can derive:

$$
\frac{T}{T_{\mathrm{s}}}=1+\Psi \theta
$$

in which $\Psi$ is a measure for the temperature dependence of the reaction rate.

Eliminating the transfer terms, differentiating eqs (16) and (17) and introducing the dimensionless variables as defined above, the resulting dimensionless equations are:

$$
\begin{array}{r}
X_{i}\left(\frac{\mathrm{d} \Phi_{\mathrm{L}}}{\mathrm{d} Z}\right)+\Phi_{\mathrm{L}}\left(\frac{\mathrm{d} X_{i}}{\mathrm{~d} Z}\right)-\eta R_{\mathrm{prod}, i} D a=0 \\
\text { for } i=\mathrm{A}, \mathrm{B}, \mathrm{C}
\end{array}
$$

$$
\begin{aligned}
& y_{\mathrm{sol}}\left(\frac{\mathrm{d} \Phi_{\mathrm{G}}}{\mathrm{d} Z}\right)+\Phi_{\mathrm{G}}\left(\frac{\mathrm{d} y_{\mathrm{sol}}}{\mathrm{d} Z}\right)+\frac{X_{\text {sol }}\left(\frac{\mathrm{d} \Phi_{\mathrm{L}}}{\alpha}\right)}{\mathrm{d} Z} \\
&+ \frac{\Phi_{\mathrm{L}}}{\alpha}\left(\frac{\mathrm{d} X_{\text {sol }}}{\mathrm{d} Z}\right)=0 \\
&\left(1-y_{\mathrm{sol}}-y_{\mathrm{w}}\right)\left(\frac{\mathrm{d} \Phi_{\mathrm{G}}}{\mathrm{d} Z}\right)-\Phi_{\mathrm{G}}\left\{\left(\frac{\mathrm{d} y_{\text {sol }}}{\mathrm{d} Z}\right)+\left(\frac{\mathrm{d} y_{\mathrm{w}}}{\mathrm{d} Z}\right)\right\} \\
&-\frac{\eta R_{\mathrm{prod}, \mathrm{H}} D a}{\alpha}=0
\end{aligned}
$$

$$
\begin{aligned}
& D a \sum_{j=1}^{3} \eta R_{j} \Delta T_{\mathrm{ad}, \mathrm{j}}-\left(C_{\mathrm{pL}} M_{\mathrm{L}} \Phi_{\mathrm{L}}\right. \\
&+\left.C_{\mathrm{pG}} M_{\mathrm{G}} \Phi_{\mathrm{G}} \frac{\beta}{\gamma}\right) \Psi\left(\frac{\mathrm{d} \theta}{\mathrm{d} Z}\right) \\
&-\left(\frac{1}{\gamma}\right)\left\{y_{\mathrm{sol}}\left(\frac{\mathrm{d} \Phi_{\mathrm{G}}}{\mathrm{d} Z}\right)+\Phi_{\mathrm{G}}\left(\frac{\mathrm{d} y_{\mathrm{sol}}}{\mathrm{d} Z}\right)\right\} \Delta T_{\mathrm{ev}, \mathrm{sol}} \\
&-\left(\frac{1}{\gamma}\right)\left\{y_{\mathrm{W}}\left(\frac{\mathrm{d} \Phi_{\mathrm{G}}}{\mathrm{d} Z}\right)+\Phi_{\mathrm{G}}\left(\frac{\mathrm{d} y_{\mathrm{w}}}{\mathrm{d} Z}\right)\right\} \Delta T_{\mathrm{ev}, \mathrm{w}}=0 \\
& \frac{\mathrm{d} y_{\mathrm{sol}}}{\mathrm{d} Z}=F_{\mathrm{MT}} \Psi\left(\frac{\mathrm{d} \theta}{\mathrm{d} Z}\right)+F_{\mathrm{Mw}}\left(\frac{\mathrm{d} X_{\mathrm{w}}}{\mathrm{d} Z}\right) \\
&+F_{\mathrm{MM}}\left(\frac{\mathrm{d} X_{\mathrm{sol}}}{\mathrm{d} Z}\right) \\
& \frac{\mathrm{d} y_{\mathrm{w}}}{\mathrm{d} Z}=F_{\mathrm{WT}} \Psi\left(\frac{\mathrm{d} \theta}{\mathrm{d} Z}\right)+F_{\mathrm{wM}}\left(\frac{\mathrm{d} X_{\mathrm{sol}}}{\mathrm{d} Z}\right) \\
&+F_{\mathrm{ww}}\left(\frac{\mathrm{d} X_{\mathrm{w}}}{\mathrm{d} Z}\right) .
\end{aligned}
$$

Equation (22b) indicates that $\sum X_{i}>1$ because of the evapuration of the solvent.

The initial conditions at the entrance of the catalyst bed follow from the dimensionless balances over the mixer:

$$
\begin{gathered}
y_{\mathrm{sol}(Z=0)}=\left(\frac{P_{\mathrm{sol}}^{0}\left(T_{(Z=0)}\right)}{P_{\mathrm{sol}}^{0}\left(T_{0}\right)}\right) y_{\mathrm{sol}, 0} \\
y_{\mathrm{H}(Z=0)}=1-y_{\mathrm{sol}(Z=0)} \\
\Phi_{\mathrm{G}(Z=0)}=1 / y_{\mathrm{sol}(Z=0)} \\
\Phi_{\mathrm{L}(Z=0)}=1-(1 / \gamma) y_{\mathrm{sol}(Z=0)} \Phi_{\mathrm{G}(Z=0)}
\end{gathered}
$$

$$
\Delta T_{\text {mixer }}=\frac{\Delta T_{\mathrm{ev}, \text { sol }} y_{\mathrm{sol}(Z=0)} \Phi_{\mathrm{G}(Z=0)}}{C_{\mathrm{pL}(Z=0)} M_{\mathrm{L}(Z=0)} \Phi_{\mathrm{L}(Z=0)} \gamma+\beta C_{\mathrm{pG}(Z=0)} M_{\mathrm{G}(Z=0)} \Phi_{\mathrm{G}(Z=0)}} .
$$

The terms $F_{i j}$ in eqs $(22 \mathrm{~g})$ and $(22 \mathrm{~h})$ are analytical functions resulting from the differentiation of eqs (16) and (17) and are defined as:

$$
\begin{aligned}
F_{i T} & =\left(\frac{\gamma_{i}}{P}\right) x_{i} T_{S}\left(\frac{\mathrm{d} P_{i}^{0}}{\mathrm{~d} T}\right) \\
F_{i i} & =\left(\frac{P_{i}^{0}}{P}\right) x_{i} x_{\text {A.० }}\left(\frac{\mathrm{d} \gamma_{i}}{\mathrm{~d} x_{i}}\right)
\end{aligned}
$$




$$
F_{j i}=\left(\frac{P_{i}^{O}}{P}\right) x_{i} x_{A, 0}\left(\frac{\mathrm{d} y_{i}}{\mathrm{~d} x_{j}}\right) .
$$

Using the definition of $\theta$ and $\Psi$ we can write the reaction rate constants $k_{i}(T)$ as:

$$
k_{i}(T)=k_{i}\left(T_{\mathrm{S}}\right) \Theta^{\omega_{i}}
$$

with

$$
\omega_{i}=E_{i} / E_{1}
$$

and

$$
\Theta=\exp \left(\frac{\theta}{1+\Psi \theta}\right)
$$

For the adsorption constants we can derive:

$$
K_{i}(T)=K_{i}\left(T_{S}\right) \Theta^{\delta_{i}}
$$

with

$$
\delta_{i}=\left(-\Delta H_{a i}\right) / E_{1} .
$$

With these definitions the dimensionless reaction rate equation $R_{i}=\frac{r_{i}}{\rho_{\mathrm{cat}} k_{1, \mathrm{~s}}}$ can now be written as:

$$
\begin{aligned}
R_{i}=\lambda_{i} & \left\{\frac{\left(K_{1, s} C_{\mathrm{A} 0}\right) \frac{\rho_{\mathrm{L}}}{M_{\mathrm{L}}} \kappa_{i} X_{i} \Theta^{\left(\omega_{i}+d_{j}\right)}}{1+\left(K_{1, \mathrm{~S}} C_{\mathrm{A} 0}\right) \frac{\rho_{\mathrm{L}}}{M_{\mathrm{L}}} \sum_{j=1}^{3} \kappa_{j} X_{j} \Theta^{\delta_{j}}}\right\} \\
& \times \frac{\left(\frac{K_{\mathrm{HS}} P_{\mathrm{S}}}{R T_{\mathrm{S}}}\right) \frac{y_{\mathrm{H}} P_{\mathrm{H}}}{1+\Psi \theta} \Theta^{\delta_{\mathrm{H}}}}{\left(1+\left(\frac{K_{\mathrm{HS}} P_{\mathrm{S}}}{R T_{\mathrm{S}}}\right) \frac{y_{\mathrm{H}} P_{\mathrm{H}}}{1+\Psi \theta} \Theta^{\delta_{\mathrm{H}}}\right)}
\end{aligned}
$$

in which

$$
\lambda_{i}=\frac{k_{i, s}}{k_{1, s}} \quad \text { and } \quad \kappa_{i}=\frac{K_{i, s}}{K_{1, s}} .
$$

In this equation the concentrations are converted to mole fractions using $C_{i}=\left(\rho_{\mathrm{L}} / M_{\mathrm{L}}\right) x_{i}$. Then $\left(C_{i} / C_{\mathrm{A} 0}\right)$ can be written as $\left(\rho_{\mathrm{L}} / M_{\mathrm{L}}\right) X_{i}$ in which $\rho_{\mathrm{L}}$ is the dimensionless liquid phase density defined analogously to the dimensionless molar weight $M_{\mathrm{L}}$.

The dimensionless groups in the differential equations are as follows.

The Damköhler number, which is a measure for the residence time in the reactor:

$$
D a=\frac{\eta_{\mathrm{D}} \rho_{\mathrm{cat}} k_{1, \mathrm{~S}} L}{\phi_{\mathrm{LO}} x_{\mathrm{A}, \mathrm{o}}}
$$

The molar ratio of hydrogen to $A$ in the feed:

$$
\alpha=\frac{\phi_{\mathrm{GO}}}{\phi_{\mathrm{LO}} x_{\mathrm{A}, \mathrm{O}}} .
$$

If we define $n_{i}$ as the number of moles of hydrogen needed for a complete conversion of 1 mole of $A$ into product $i$ we can define a supply ratio $\alpha_{i}$ as:

$$
\alpha_{i}=\alpha / n_{i}
$$

The respective values for $n_{i}$ are $n_{\mathrm{B}}=2, n_{\mathrm{C}}=6$ and $n_{\mathrm{P}}$ $=9$. With this definition a value of $\alpha_{i}=1$ means that we feed exactly enough hydrogen to convert all $A$ to product $i$. For industrial purposes it is advantageous to keep $\alpha_{i}$, if $i$ is the desired product, as close to 1 as possible to avoid hydrogen losses or high recycle ratios for non-converted hydrogen.

The molar ratio of the liquid to the gas feed rate:

$$
\gamma=\frac{\phi_{\mathrm{LO}}}{\phi_{\mathrm{GO}}}
$$

The ratio of the heat capacities of the gas and liquid phases at the entrance of the mixer:

$$
\beta=\frac{C_{\mathrm{pG}, 0} M_{\mathrm{G}, 0}}{C_{\mathrm{pL}, 0} M_{\mathrm{L}, 0}}
$$

Often the dimensionless groups $\gamma$ and $\beta$ appear together as $\beta / \gamma$ and are defined as one single dimensionless group. We define them as two separate dimensionless groups because in our case they appear independently in our equations.

The adiabatic temperature rise for each reaction step:

$$
\Delta T_{\mathrm{ad}, i}=\frac{\left(-\Delta H_{\mathrm{ri}}\right) x_{\mathrm{A}, \mathrm{o}}}{C_{\mathrm{pL}, \mathrm{o}} M_{\mathrm{L}, \mathrm{o}} T_{\mathrm{S}}}
$$

A measure for the adiabatic temperature decrease due to complete evaporation of the solvent:

$$
\Delta T_{\mathrm{ev}, i}=\frac{\Delta H_{\mathrm{ev}, i}}{C_{\mathrm{pL}, \mathrm{o}} M_{\mathrm{L}, \mathrm{o}} T_{\mathrm{S}}}
$$

A measure for how close to the boiling point the feed temperature is chosen:

$$
y_{\mathrm{sol}, 0}=\frac{P_{\mathrm{sol}}^{\mathrm{o}}\left(T_{\mathrm{o}}\right)}{P} .
$$

$y_{\text {sol, o }}$ can be seen as the mole fraction solvent in the gas phase if the gas phase were saturated with the solvent at the feed temperature or if the mixer were isothermic instead of adiabatic.

The dimensionless adiabatic temperature decrease over the mixer:

$$
\Delta T_{\text {mixor }}=\frac{T_{0}-T_{(Z=0)}}{T_{S}}
$$

A measure for the adsorption strength of the reactant on the catalyst surface:

$$
K_{1, s} C_{\mathrm{AO}}
$$

A measure for the adsorption strength of hydrogen on the catalyst surface:

$$
\frac{K_{\mathrm{HS}} P_{\mathrm{S}}}{R T_{\mathrm{S}}}
$$

The initial conditions for the solution of the model equations are:

$$
\begin{aligned}
X_{i} & =x_{i(Z=0)} / x_{\mathrm{A}, 0} \\
y_{\mathrm{sol}} & =y_{\mathrm{sol}(\mathrm{Z}=0)}
\end{aligned}
$$




$$
\begin{aligned}
y_{\mathrm{H}} & =1-y_{\mathrm{sol}} \\
\theta & =-\left(E_{1} / R T_{\mathrm{S}}\right)\left(1-T_{(\mathrm{Z}=0)} / T_{\mathrm{S}}\right) \\
\Phi_{\mathrm{L}} & =\phi_{\mathrm{L}(\mathrm{Z}=0)} / \phi_{\mathrm{L} 0} \\
\Phi_{\mathrm{G}} & =\phi_{\mathrm{G}(Z=0)} / \phi_{\mathrm{GO} .}
\end{aligned}
$$

The above system of simultaneous first order differential equations with these initial conditions was solved on an HP9816S microcomputer using a fourth order Runge-Kutta procedure with Gill parameters.

\section{PLUG FLOW RESULTS}

\subsection{Temperature decrease in the mixer}

The temperature decrease over the mixer is a function of the feed temperature $T_{0}$, the reactor pressure $P$, the ratios of the gas and liquid feed flows and heat capacities, the heat of evaporation of the solvent and the vapour pressure curve of the solvent. The dimensionless parameters governing the temperature decrease over the mixer are $y_{\mathrm{sol}, 0}, \gamma, \beta$ and $\Delta T_{\mathrm{ev}, \mathrm{sol}}$. For a given gas-liquid system $\Delta T_{\mathrm{ev}, \text { sol }}$ and $\beta$ are constant and the temperature drop is only influenced by the other two parameters.

In Fig. 4 the temperature decrease over the mixer is given for the system methanol/hydrogen as a function of the parameter $y_{\text {sol. } o}$ and $\gamma$ for two values of the reactor pressure. From this figure it is seen that as $y_{\text {sol, }}$ increases the temperature drop increases, because the liquid is fed at a temperatare closer to the boiling point. The temperature drop also increases if the ratio of gas and liquid flow rate $y$ decreases. This is caused by the fact that more solvent must evaporate to saturate the relatively larger gas flow.

\subsection{Model simulations}

Typical results from a model run are shown in Fig. 5. In Fig. 5(a) the product distribution is given as a function of the axial coordinate $Z$. It is clear from this figure that our reactions show molecular queueing. i.e. the reaction from reactant $i+1$ to reactant $i+2$ can only proceed after all $i$ has been

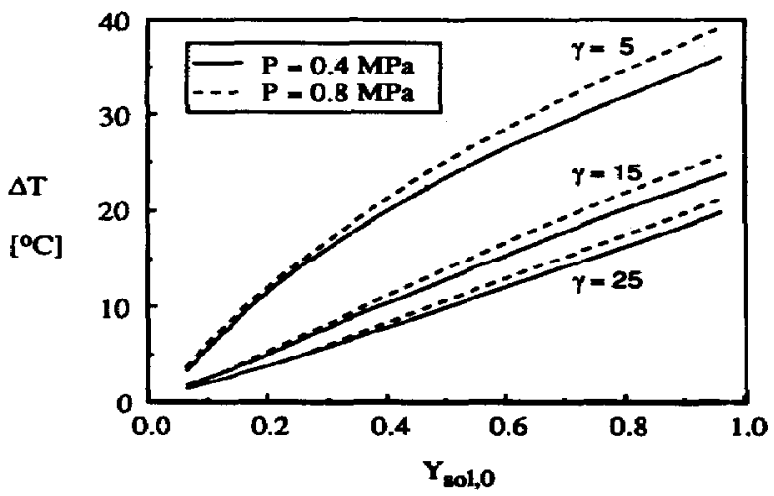

Fig. 4. Calculated temperature decrease over the mixer as a function of the ratio of liquid feed flow rate over the gas feed flow rate $\gamma$, the reactor pressure $P$ and the parameter $Y_{\text {*ol }}$ $=P_{\mathrm{sol}}^{\mathrm{o}}\left(T_{\mathrm{o}}\right) / P$. converted into $i+1$. This is caused by the large differences in adsorption constants between the reactants, resulting in an effective zero order behaviour over a large concentration range. The temperature distribution in the reactor is given in Fig. 5(b). The temperature at $Z=0$ is not equal to the feed temperature because of the temperature decrease in the mixer. Under these circumstances the temperature rise in the reactor (defined as the maximum temperature in the reactor minus the feed temperature) is only $30.5^{\circ} \mathrm{C}$ even though all $\mathrm{A}$ is converted into $\mathrm{P}$ and the adiabatic temperature rise for the liquid phase is $170^{\circ} \mathrm{C}$. The effect of the evaporation on the flow rates is given in Fig. 5(c). The gas flow rate increases because more than 1 mole of methanol evaporates for each mole of hydrogen consumed! The liquid flow rate decreases because of the evaporation of methanol. In Fig. 5(d) the composition of the gas phase is given. It should be noted that the mole fraction of water in the gas phase is very small: the evaporation of water hardly contributes to the total heat removal in the reactor. This is due to the much higher concentration and volatility of methanol compared to that of water. In Fig. 5(e) the mole fractions of methanol and water in the liquid phase are given. An important aspect of this type of reaction system is the amount of heat that is absorbed by the evaporation of the solvent. In Fig. 5(f) the contribution to the heat removal of the various terms in the enthalpy balance are given as a function of the axial position in the bed, and are expressed as the fraction of the total amount of reaction heat produced at complete conversion. These terms are the heat liberated by the reaction, the heat removal by the gas, the liquid and by the evaporation of the solvent and the reaction water.

At $Z=0$ the gas and the liquid have passed the mixing chamber where part of the liquid has evaporated resulting in a negative contribution by the gas and liquid streams and a positive contribution by the evaporation of the solvent.

At $100 \%$ conversion approximately $75 \%$ of the reaction heat is absorbed by the evaporation of the solvent. The evaporation of the water formed during the reaction accounts for only $3 \%$ of the total heat removal.

\subsection{Influence of the operating parameters}

In the following simulations the concentration of the reactant $A$ in the feed was chosen at 0.220 $\mathrm{kmol} / \mathrm{m}^{3}$ unless stated otherwise.

6.3.1. The influence of the hydrogen supply ratio $\alpha_{P}$ related to the final product $P$. The influence of $\alpha_{P}$ can be illustrated as follows. As long as $\alpha_{P} \leqslant 1$ the maximum conversion is limited by the hydrogen supply and equal to $\alpha_{\mathrm{p}}$. Starting from $\alpha_{\mathrm{p}}=0$ and increasing the gas feed rate the conversion will increase and so will the maximum temperature. The temperature will increase with increasing $\alpha_{p}$ until it is close to the boiling point of the mixture. Close to the boiling point 

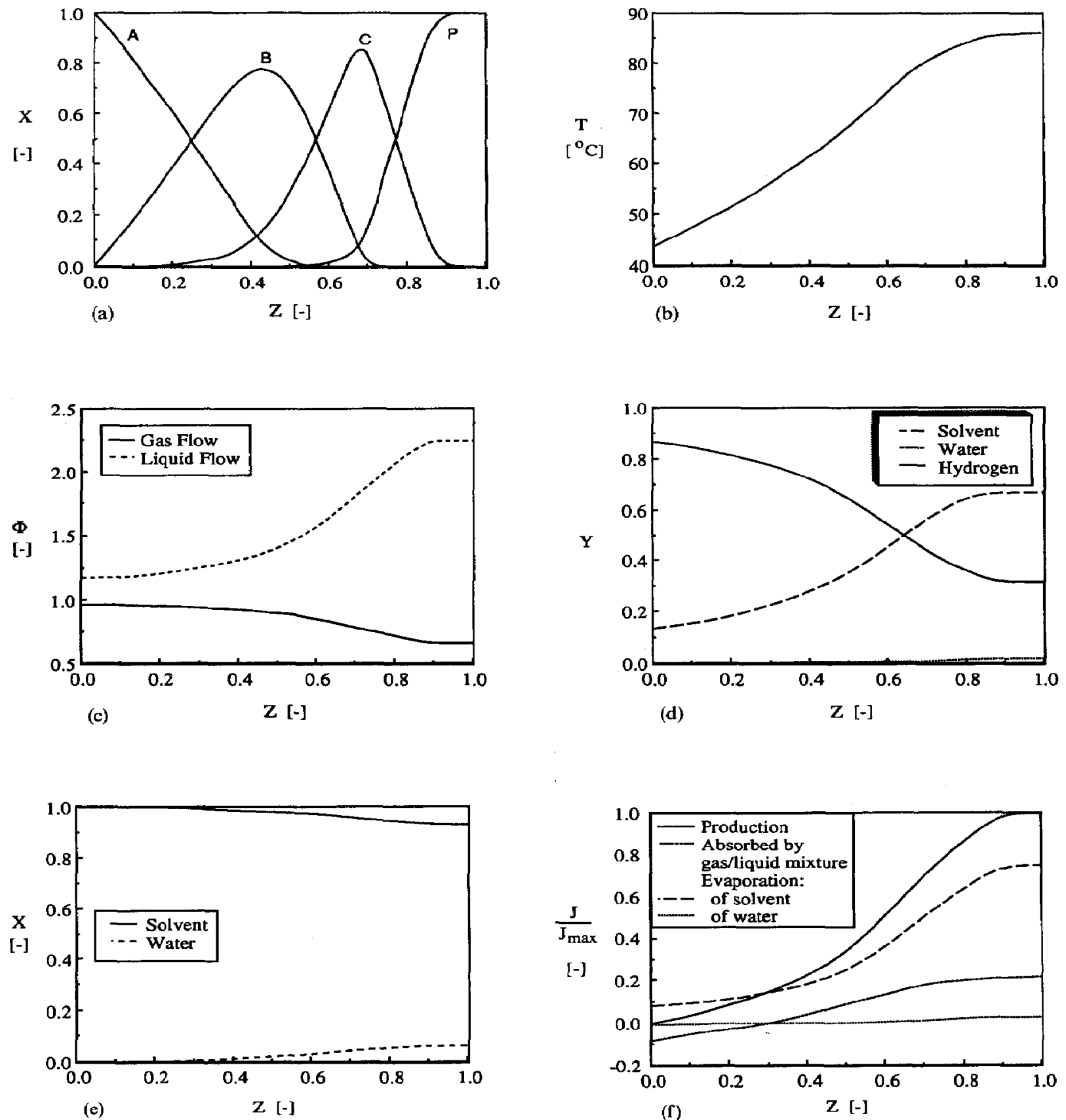

Fig. 5. Calculated profiles of the normalized mole fraction of the reactants in the liquid phase (a), the temperature profile (b), the dimensionless gas and liquid flow rates (c), the composition of the gas phase (d), the composition of the liquid phase (e) and the contribution of the various processes to the heat removal (f). $J$ is the enthalpy consumed or produced. $J_{\max }$ is the total amount of reaction enthalpy produced. The normalized mole fraction is defined as $X_{i} / \sum X$. The model parameters are $D a=10, \alpha_{\mathrm{p}}=3.15, y=4.0, \eta$ $=1.0, T_{0}=55^{\circ} \mathrm{C}$ and $P=0.4 \mathrm{MPa}$.

practically all heat produced by the reaction is absorbed by evaporation so that a further increase in $\alpha_{\mathbf{p}}$ will hardly affect the temperature. The boiling point of the mixture will never be reached because at that point the hydrogen partial pressure is equal to zero, so no further reaction occurs. As long as $\alpha_{p} \leqslant 1$, practically all hydrogen will be consumed and the hydrogen partial pressure will drop to low values. As a result the reaction practically stops due to the low concentration of hydrogen and thus the temperature, the conversion and the liquid and gas phase compositions will remain constant. This is shown in Fig. 6(a) and (b) where the calculated temperature and conversion profiles are given for $\alpha_{\mathrm{p}}=0.6$. 

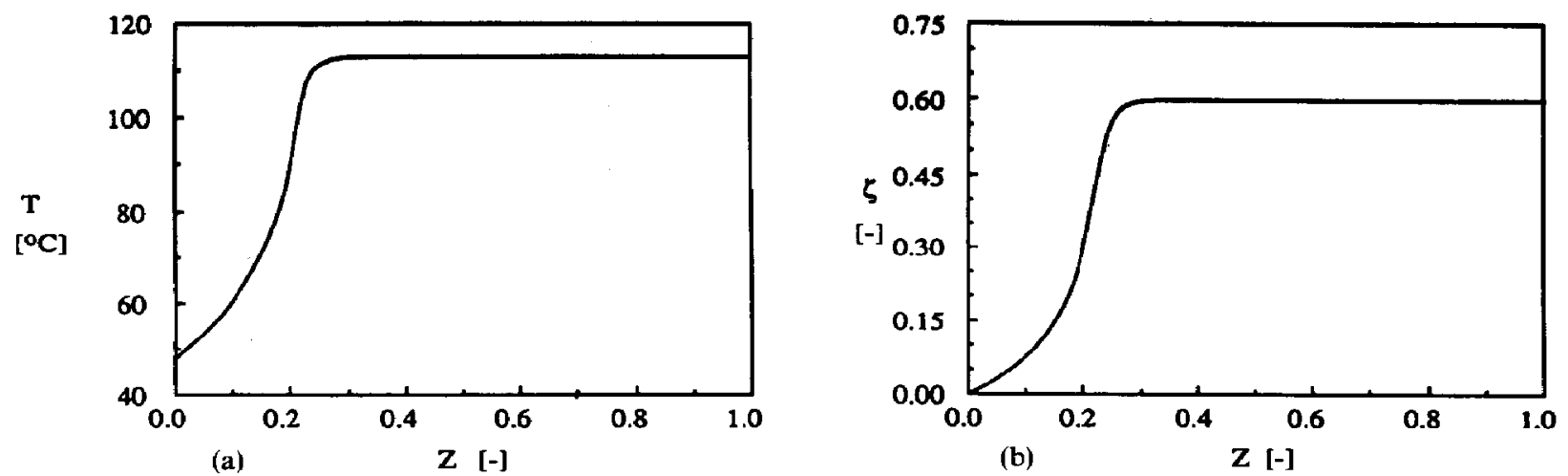

Fig. 6. Temperature (a) and conversion (b) profiles for a hydrogen supply ratio of 0.6. Parameter values are $D a=12, \alpha_{\mathrm{P}}=0.60, \gamma=21.2, \eta=1, T_{0}=50^{\circ} \mathrm{C}$ and $P=0.4 \mathrm{MPa}$.

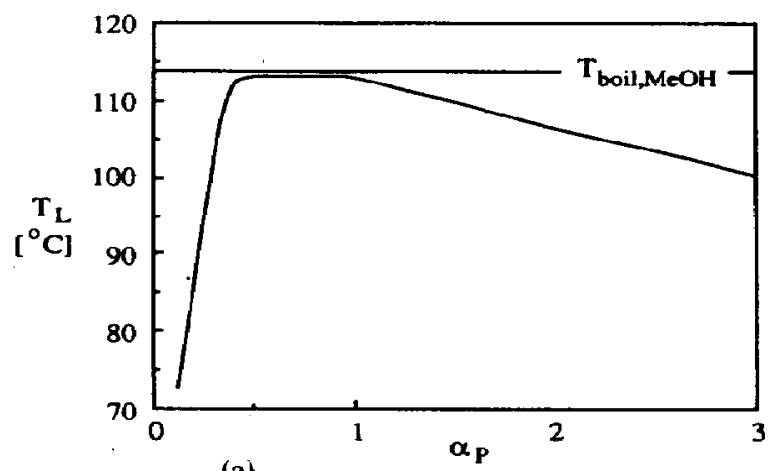

(a)

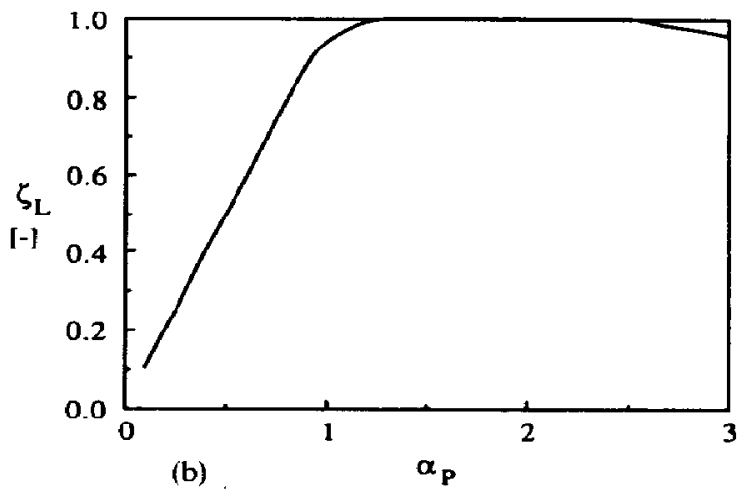

(b)

Fig. 7. Influence of the hydrogen supply ratio $\alpha_{p}$ on the maximum temperature in the catalyst bed (a) and on the conversion at the exit of the reactor (b). Parameter values are $D a=5, \eta=1, T_{0}=55^{\circ} \mathrm{C}$ and $P$ $=0.5 \mathrm{MPa}$.

An increase of $\alpha_{\mathrm{p}}$ beyond $\alpha_{\mathrm{p}}=1$ will result in lower reactor temperatures because of the additional evaporation; this does not directly result in a lower conversion because of the increase in the hydrogen partial pressure. At very high values of $\alpha_{p}$ the influence of the lower temperatures becomes dominant and then the conversion decreases with increasing $\alpha_{P}$ as is illustrated in Fig. 7. This behaviour was illustrated experimentally in Part $I$.

6.3.2. The influence of the feed temperature $T_{0}$. The influence of the feed temperature $T_{0}$ is moderated due to the presence of the mixer. Raising $T_{0}$ will result in an increase for $T_{(z=0)}$, but this increase will be smaller than the increase in $T_{0}$ because more solvent will evaporate in the mixer, resulting in a larger temperature decrease over the mixer. This moderation is a very useful property of this reactor system. A sudden disturbance in the feed temperature will be smaller at the entrance of the catalyst bed.

An increase of $T_{0}$ will result in an increase of $T_{(z=0)}$ and this will cause the reaction rate to increase. On the other hand this temperature increase will result in a higher partial pressure of the mixture and conse- quently the partial pressure of hydrogen is lowered, slightly compensating for the effect of the temperature increase on the reaction rate. The influence of the feed temperature on the conversion and the temperature profiles in the catalyst bed is given in Fig. 8(a) and (b).

6.3.3. The influence of the reactor pressure. Increasing the pressure raises the boiling point of the solvent and reduces the amount of solvent that evaporates at a given temperature. When less solvent evaporates a larger part of the reaction heat can be used to increase the temperature and the temperature profiles become steeper. Also due to the lower evaporation, the partial pressure of hydrogen increases. Both effects result in an increase of the reaction rate. This is illustrated in Fig. 9(a) and (b). The influence of the reactor pressure on the temperature profiles is far greater than the influence of either the supply ratio of hydrogen $\alpha$ or the feed temperature $T_{0}$.

So far we have discussed the influence of the operating parameters on the temperature level or temperature rise in the reactor. We did so because the temperature has a very strong influence on the selectivity. Now we will discuss the influence of the 


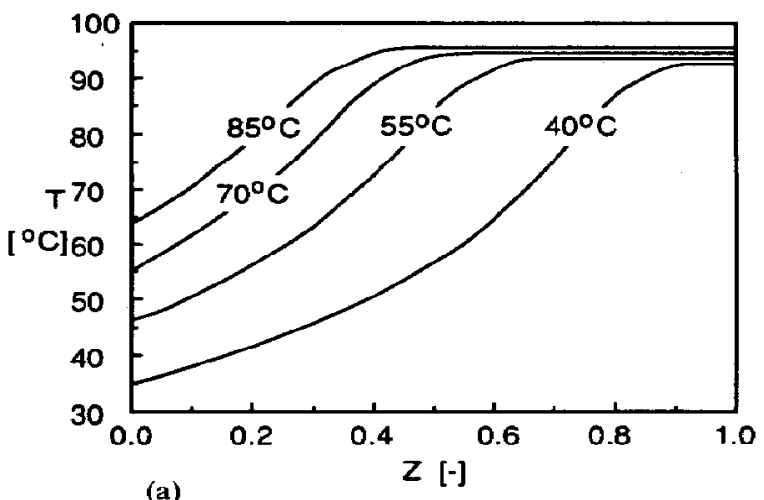

(a)

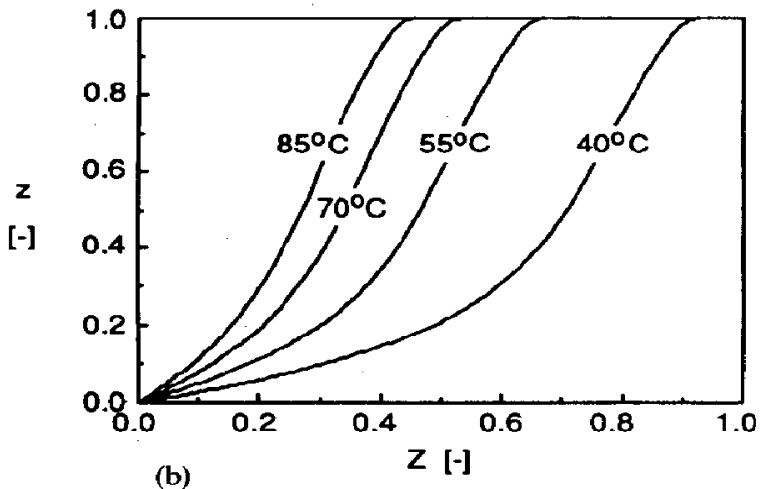

(b)

Fig. 8. Influence of the feed temperature $T_{0}$ on the calculated temperature profiles (a) and the calculated conversion profile (b) in the catalyst bed. Parameters values are $D a=10, \alpha_{\mathrm{p}}=3.1, \gamma=4.1, \eta=1$ and $P$ $=0.4 \mathrm{MPa}$.

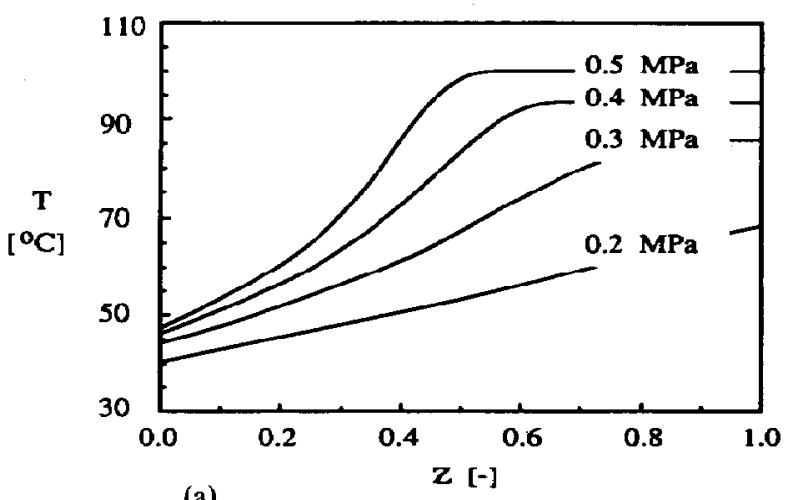

(a)

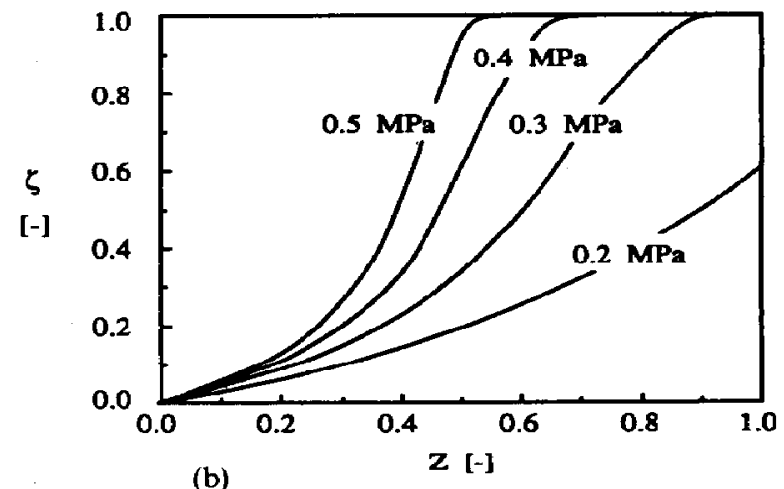

(b)

Fig. 9. Influence of the reactor pressure on the calculated temperature (a) and conversion (b) profiles in the catalyst bed. Model parameters are $\alpha_{\mathrm{p}}=3.15, D a=15, T_{\mathrm{o}}=55^{\circ} \mathrm{C}, \Delta T_{\text {ad }}=170^{\circ} \mathrm{C}, \gamma=4.17$ and $\eta=1$.

operating parameters directly on the selectivities to the intermediate products $B$ and $C$.

6.3.4. Effects on the yield. For given kinetic rate equations the yield is only dependent on the temperature level in the reactor provided that the reaction orders of the different reaction steps are the same. In our case of Langmuir-Hinshelwood type reactions the yield is determined by the differences in adsorption strength and the reaction rate parameters between the reaction intermediates.

The yield to a product $i$ is defined as the fraction of the reactant A that has been converted into $i$ :

$$
\eta_{i}=\frac{x_{i} \phi_{\mathrm{L}}}{x_{\mathrm{A} 0} \phi_{\mathrm{LO}}}=X_{i} \Phi_{\mathrm{L}}
$$

Often it is convenient to use the differential selectivity or local selectivity $\sigma_{i}^{\prime}$ which we define as the ratio of the rate with which $i$ is produced to the rate with which $i$ is converted into the next intermediate $i+1$ :

$$
\sigma_{i}^{\prime}=\frac{R_{i-1}}{R_{i}}
$$

Although the relation between the differential selectivity $\sigma_{i}^{\prime}$ and the yield $\eta_{i}$ is complicated it can be said that if $\sigma_{i}^{\prime}$ increases then $\eta_{i}$ will also increase and vice versa [see Westerterp et al.(1984)]. The effect of the temperature on the differential selectivity will therefore indicate what we can expect for the yield $\eta_{i}$.

Using eq. (30) we can derive for the differential selectivity:

$$
\sigma_{i}^{\prime}=\left(\frac{X_{i-1}}{X_{i}}\right)\left(\frac{\kappa_{i-1} \lambda_{i-1}}{\kappa_{i} \lambda_{i}}\right) \Theta^{\left(\omega_{i}-1-\omega_{i}\right)+\left(\delta_{i-1}-\delta_{i}\right)} .
$$

For a standard temperature of $350 \mathrm{~K}$ and the values for the kinetic and adsorption parameters given in Appendix A we find:

$$
\begin{aligned}
\left(\omega_{\mathrm{A}}-\omega_{\mathrm{B}}\right)+\left(\delta_{\mathrm{A}}-\delta_{\mathrm{B}}\right) & =-0.980 \\
\left(\omega_{\mathrm{B}}-\omega_{\mathrm{C}}\right)+\left(\delta_{\mathrm{B}}-\delta_{\mathrm{C}}\right) & =-0.646 \\
\frac{\kappa_{1} \lambda_{1}}{\kappa_{2} \lambda_{2}} & =4.43 \\
\frac{\kappa_{2} \lambda_{2}}{\kappa_{3} \lambda_{3}} & =19.5 .
\end{aligned}
$$


From these data we see that the exponent is negative for both $B$ and $C$, being -0.980 for $B$ and -0.646 for $C$. This means that the selectivity will decrease with increasing temperature and that the decrease will be faster for $B$ than for $C$. Furthermore, we see that the pre-exponential term is equal to 4.43 for $B$ and 19.5 for $C$, so we expect that the maximum yield of $C$ is higher than the maximum yield of $B$. This is illustrated in Fig. 1O(a) and (b) where the maximum yield of $B$ and $C$ are plotted vs $\alpha_{B}$ and $\alpha_{C}$ for several values of the reactor pressure. As explained at a higher pressure the temperature level in the reactor is also higher. For $\alpha_{i}<1$ the maximum yield to $i$ is equal to $\alpha_{i}$. Increasing $\alpha_{i}$ will result in a temperature decrease and therefore in an increase of the maximum yield. As expected the influence of $\alpha_{B}$ on $\eta_{B}$ is stronger than the influence of $\alpha_{c}$ on $\eta_{C}$.

Figure 1O(c), (d) gives the values of the residence times $D a_{B}$ and $D a_{C}$ at which the maximum yields to $B$ and $C$ respectively are reached. For $B D a_{B}$ increases with increasing $\alpha_{\mathrm{B}}$ because of the decreasing temperature level in the reactor. For $\mathrm{C}$ the situation is more complicated, as can be seen in Fig. 10(d). The decrease around $\alpha_{C}=1$ is caused by the increase of the hydrogen partial pressure, which more than compensates for the temperature decrease caused by the stronger evaporation. At higher values for $\alpha_{c}$ the temperature decrease becomes dominant.

\section{THE DISPERSION MODEL}

\subsection{Basic approach}

The dispersion model does not deviate much from the plug flow model. The differences are as follows.

1. Axial dispersion of both heat and mass in the liquid phase is taken into account.

2. The evaporation of the water formed during the reaction is neglected. The plug flow model showed that the contribution of the evaporation of water to the heat transport mechanisms was almost negligible.

3. Instead of vapour-liquid equilibrium for the solvent we now introduce a mass transfer rate equation for the evaporation of the solvent. The partial pressure of the solvent at the gas-liquid interphase is equal to the vapour pressure of the solvent.

4. Principally a dispersion equation has to be used for the solvent as well as for the reactants. Because the mole fraction of the solvent in the liquid phase is practically equal to 1 the gradients in the solvent concentration will be very small. The solvent concentration is therefore assumed constant over each differential element in the reactor.

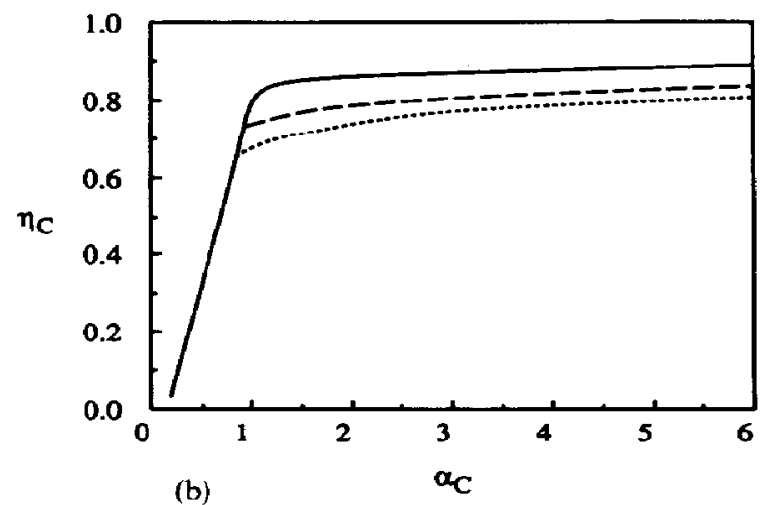

(a)

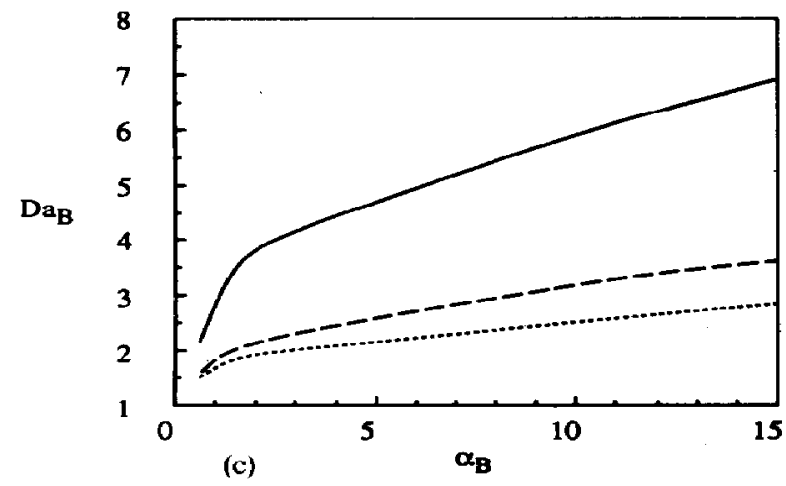

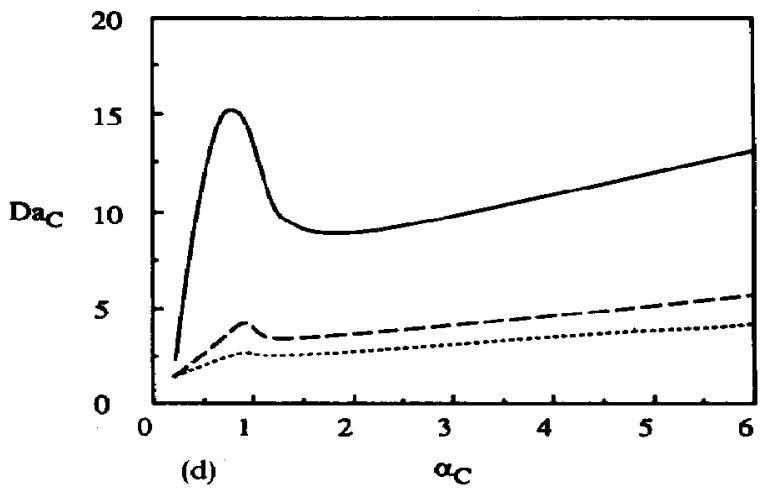

Fig. 10. Calculated maximum yield of $B(a)$ and $C$ (b) and the Damköhler number at which the maximum yield of $B$ (c) and $C$ (d) is reached as a function of the reactor pressure and the hydrogen supply ratio $\alpha_{B}$ and $\alpha_{\mathrm{C}}$ respectively. Parameters values are $D a=12, \beta=0.0176, \eta=1$ and $T_{0}=50^{\circ} \mathrm{C}$. 
In the dispersion model we describe the evaporation by means of a mass transfer equation. This seems to contradict the assumption that there are no mass transfer limitations. Including the evaporation rate in this manner gives us a direct relation for the amount of evaporated solvent, which simplifies the numerical solution of the model equations. Because the product of the mass transfer coefficient and the specific gas-liquid interfacial area is large, the gas phase will still be practically saturated with the solvent.

\subsection{Dispersion equations}

The dispersion model consists of the following dimensionless differential equations:

$$
\begin{aligned}
& \frac{1}{P e_{\mathrm{m}}}\left(\frac{\mathrm{d}^{2} X_{i}}{\mathrm{~d} Z^{2}}\right)-\Phi_{\mathrm{L}}\left(\frac{\mathrm{d} X_{i}}{\mathrm{~d} Z}\right)-X_{i}\left(\frac{\mathrm{d} \Phi_{\mathrm{L}}}{\mathrm{d} Z}\right) \\
& +\operatorname{Dan}_{i} R_{\mathrm{prod}, i}=0 \text { for } i=\mathrm{A}, \mathrm{B} \text { and } \mathrm{C} \\
& \boldsymbol{X}_{\mathrm{P}}=\frac{1}{\boldsymbol{\Phi}_{\mathrm{L}}}-\left(\boldsymbol{X}_{\mathrm{A}}+\boldsymbol{X}_{\mathrm{B}}+\boldsymbol{X}_{\mathrm{C}}\right) \\
& y_{\mathrm{H}}\left(\frac{\mathrm{d} \Phi_{\mathrm{G}}}{\mathrm{d} Z}\right)+\Phi_{\mathrm{G}}\left(\frac{\mathrm{d} y_{\mathrm{H}}}{\mathrm{d} Z}\right)-\frac{D a \eta}{\alpha} R_{\mathrm{prod}, \mathrm{H}}=0 \\
& y_{\mathrm{so} 1}\left(\frac{\mathrm{d} \Phi_{\mathrm{G}}}{\mathrm{d} Z}\right)+\Phi_{\mathrm{G}}\left(\frac{\mathrm{d} y_{\mathrm{sol}}}{\mathrm{d} Z}\right)-S t^{\prime} P\left(\frac{y_{\mathrm{sol}}^{i}-y_{\mathrm{sol}}}{1+\Theta \theta}\right)=0 \\
& \frac{\mathrm{d} \Phi_{\mathrm{L}}}{\mathrm{d} Z}+S t^{\prime} P\left(\frac{y_{\mathrm{sol}}^{i}-y_{\text {sol }}}{1+\Psi \theta}\right) \frac{1}{\gamma}=0 \\
& \frac{\Psi}{P e_{\mathrm{h}}}\left(\frac{\mathrm{d}^{2} \theta}{\mathrm{d} Z^{2}}\right)+\left(C_{\mathrm{pL}} M_{\mathrm{L}} \Phi_{\mathrm{L}}+C_{\mathrm{pG}} M_{\mathrm{G}} \Phi_{\mathrm{G}} \frac{\beta}{\gamma}\right) \Psi\left(\frac{\mathrm{d} \theta}{\mathrm{d} Z}\right) \\
& -\operatorname{Da\eta } \sum_{j=1}^{3} R_{j} \Delta T_{\text {ad. } j}-S t^{\prime} P \Delta T_{\text {ov, sol }} \\
& \times\left(\frac{y_{\text {sol }}^{i}-y_{\text {sol }}}{1+\Psi \theta}\right) \frac{1}{\gamma}=0 \\
& X_{\mathrm{sol}}=\frac{1}{x_{\mathrm{A}, 0}}-\left(X_{\mathrm{A}}+X_{\mathrm{B}}+X_{\mathrm{C}}+X_{\mathrm{P}}\right) \\
& \sum y_{i}=1 \text {. }
\end{aligned}
$$

The boundary conditions for these equations are (see Fig. 11):

At $Z=0$

$$
\begin{aligned}
&\left(C_{\mathrm{pG}} M_{\mathrm{G}} \Phi_{\mathrm{G}} \beta+C_{\mathrm{pL}} M_{\mathrm{L}} \Phi_{\mathrm{L}}\right)\left(\theta_{\left(Z=0^{-}\right)}-\theta_{\left(Z=0^{+}\right)}\right)+\left.\frac{1}{P e_{\mathrm{h}}} \frac{\mathrm{d} \theta}{\mathrm{d} Z}\right|_{Z=0^{+}}=0 \\
&\left.\frac{\mathrm{d} X_{i}}{\mathrm{~d} Z}\right|_{Z=0^{+}}-P e_{\mathrm{m}} X_{i, Z=0^{+}}=-P e_{\mathrm{m}} X_{i, Z=0^{-}} \\
& y_{\mathrm{sol}}=y_{\mathrm{sol}, Z=0^{-}} \\
& y_{\mathrm{H}}=1-y_{\mathrm{sol}} \\
& \Phi_{\mathrm{L}}=\Phi_{\mathrm{L}, Z=0^{-}} / \phi_{\mathrm{LO}} \\
& \Phi_{\mathrm{G}}=\Phi_{\mathrm{G}, Z=0^{-}} / \phi_{\mathrm{GO}} .
\end{aligned}
$$

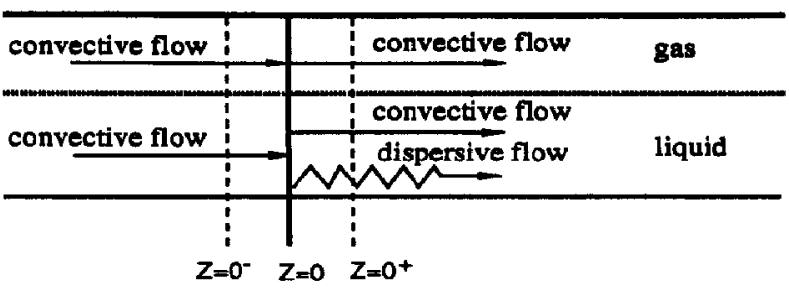

Fig. 11. Boundary condition for the dispersion model around $Z=0$. Conditions at $Z=0^{-}$follow from the balances around the mixer.

At $Z=1$

$$
\frac{\mathrm{d} \theta}{\mathrm{d} Z}=\frac{\mathrm{d} X_{\mathrm{i}}}{\mathrm{d} Z}=0 .
$$

The conditions at $Z=0^{-}$follow from the balances around the mixer.

The model was solved using a finite difference method in which a backward discretization was used for the first differentials in the second order boundary equations for $\theta$ and $X_{i}$. This is described in more detail in Appendix B. The difference equations were solved on a VAX8650 mainframe computer. Generally $\mathbf{4 0 0}$ discretization points resulted in sufficiently accurate results.

All dimensionless groups and variables are defined as in the plug flow model. New dimensionless groups in these equations are as follows.

A modified Stanton number or the number of transfer units:

$$
S t^{\prime}=\left(\frac{k_{\mathrm{g}} a_{\mathrm{g}} \varepsilon_{\mathrm{G}} L}{\phi_{\mathrm{L} O}}\right)\left(\frac{P_{\mathrm{S}}}{R T_{\mathrm{S}}}\right) .
$$

The Peclet number for mass dispersion:

$$
P e_{\mathrm{m}}=\frac{\left(\frac{M_{\mathrm{LO}}}{\rho_{\mathrm{LO}}}\right) \phi_{\mathrm{L} 0} L}{\varepsilon_{\mathrm{L}} D_{\mathrm{ax}}} \equiv \frac{U_{\mathrm{L} O} L}{\varepsilon_{\mathrm{L}} D_{\mathrm{ax}}} .
$$

The Peclet number for heat dispersion:

$$
P e_{\mathrm{h}}=\frac{C_{\mathrm{pL} .0} M_{\mathrm{LO}} \phi_{\mathrm{LO}} L}{\lambda_{\mathrm{eff}}}
$$

\section{RESULTS WITH THE DISPERSION MODEL}

We will first illustrate the influence of the new dimensionless groups in the model on several variables.

\subsection{Influence of $\mathrm{St}^{\prime}$}

The influence of $S t^{\prime}$ on the temperature profile is given in Fig. 12. From this figure we see that decreasing $S t^{\prime}$ results in a decrease of the temperature, which is a rather unexpected result. Increasing the gas-liquid mass transfer rate we would expect a temperature decrease because more solvent evaporates. Instead our model predicts a slight temperature increase. The reason for this is that the total heat capacity of the gas-liquid mixture decreases drastically when more 


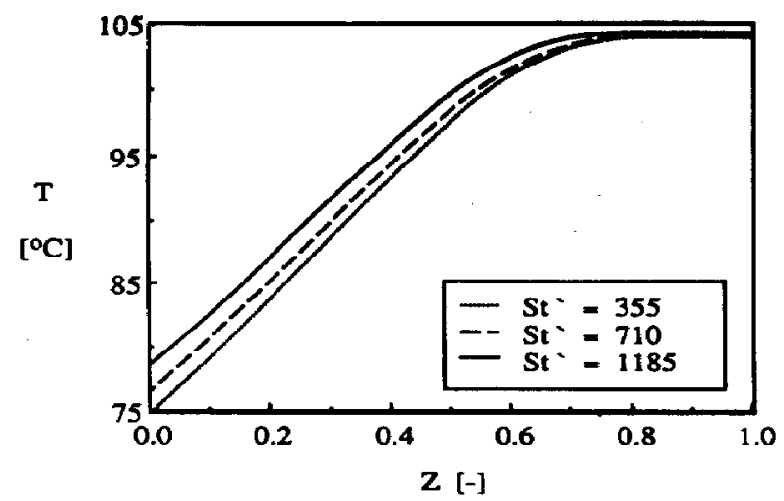

Fig. 12. Influence of $S t^{\prime}$ on the calculated temperature profile in the catalyst bed. Parameter values, are $D a=7.0, T_{0}$ $=55^{\circ} \mathrm{C}, P e_{\mathrm{m}}=20, P e_{\mathrm{h}}=1, \alpha_{\mathrm{p}}=2.4, T_{\mathrm{o}}=50^{\circ} \mathrm{C}, \eta=0.3$ and $\gamma=5.4$.

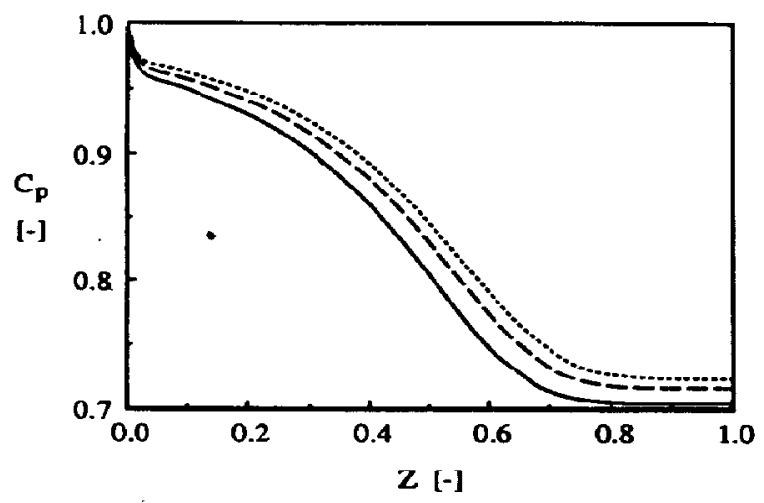

Fig. 13. Influence of $S t^{\prime}$ on the dimensionless total heat capacity of the gas-liquid mixture. Line types identifying curves are defined in Fig. 12. Parameter values as in Fig. 12.

solvent evaporates. Thus, when $S t^{\prime}$ increases the total heat capacity decreases. The overall result is that even though more solvent evaporates and thus less energy is available to increase the temperature, the temperature increase will nevertheless be larger due to the decrease in $C_{\mathrm{p}}$. The total heat capacity profile of the gas-liquid mixture is given in Fig. 13. In this figure $C_{p}$ is defined as $\left(C_{\mathrm{pL}} M_{\mathrm{L}} \Phi_{\mathrm{L}}+C_{\mathrm{pG}} M_{\mathrm{G}} \Phi_{\mathrm{G}} \frac{\beta}{\gamma}\right) /\left(1+\frac{\beta}{\gamma}\right)$. $\left(1+\frac{\beta}{\gamma}\right)$ is the dimensionless heat capacity of the feed when $M_{\mathrm{G}}, M_{\mathrm{L}}, C_{\mathrm{pG}}, C_{\mathrm{pL}}, \Phi_{\mathrm{L}}$ and $\Phi_{\mathrm{G}}$ are equal to 1 .

The influence of $S t^{\prime}$ on the saturation of the gas phase is given in Fig. 14. The assumption that the gas phase is saturated with solvent would be wrong only for very low values of $S t^{\prime}$. In our miniplant the values for $S t^{\prime}$ are estimated to vary between 400 and 800 , so we can safely assume that the gas phase is indeed saturated with the solvent.

\subsection{Influence of $\mathrm{Pe}_{m}$}

The influence of $P e_{m}$ on the conversion profile is given in Fig. 15(a). The influence of $P e_{m}$ on the con-

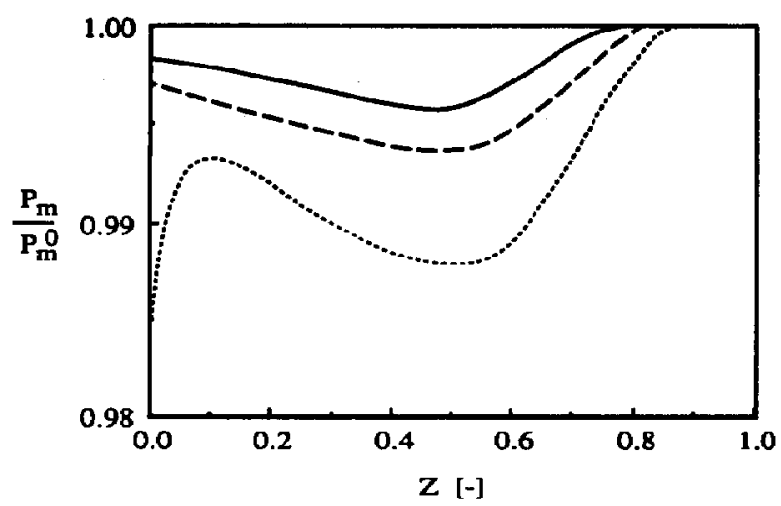

Fig. 14. Influence of $S t^{\prime}$ on the saturation of the gas phase with the solvent. Line types identifying the curves are defined in Fig. 12. Parameter values as in Fig. 12.

centration profiles for the two intermediates is given in Fig. 15(b) and (c). It is clear that an increase of the mass dispersion has a strong negative influence on the selectivities. In our laboratory we extensively studied the residence time distribution for the system methanol-hydrogen in a cocurrent upflow packed bed reactor at elevated pressure and for isothermal operation [see van Gelder and Westerterp (1990)]. From the results obtained during this study we estimate the value for $P e_{m}$ in our reactor to vary between 7 and 9, depending on the gas and liquid flow rates and the reactor pressure.

\subsection{Influence of $\mathrm{Pe}_{h}$}

The influence of $P e_{\mathrm{h}}$ on the temperature profile is given in Fig. 16(a). As $P e_{\mathrm{h}}$ becomes smaller the temperature in the first part of the reactor will rise, resulting in a larger reaction rate. This is illustrated in Fig. 16(b) where the conversion is plotted vs $P e_{h}$. This increase in the temperature level of the reactor increases the reactor capacity. The profiles in Fig. 16 show that the reactor is very sensitive to variations in the heat dispersion. In our case an increase in the temperature level is disadvantageous because it decreases the selectivities towards the intermediate products, as was discussed earlier.

\section{COMPARISON BETWEEN MODEL AND EXPERIMENT}

In Part I we presented experimental results on the hydrogenation of 2,4,6-trinitrotoluene in methanol obtained in our miniplant. Here we will compare some of our results to model simulations, but first we will discuss some of the model limitations that are inherent to modelling such complicated reaction systems.

\subsection{Model choice and its limitations}

9.1.1. Plug flow versus dispersion model. For a packed bubble column the validity of the assumption of plug flow in the liquid phase and of no axial heat conduction is highly questionable. The plug flow model was set up and discussed extensively because of 

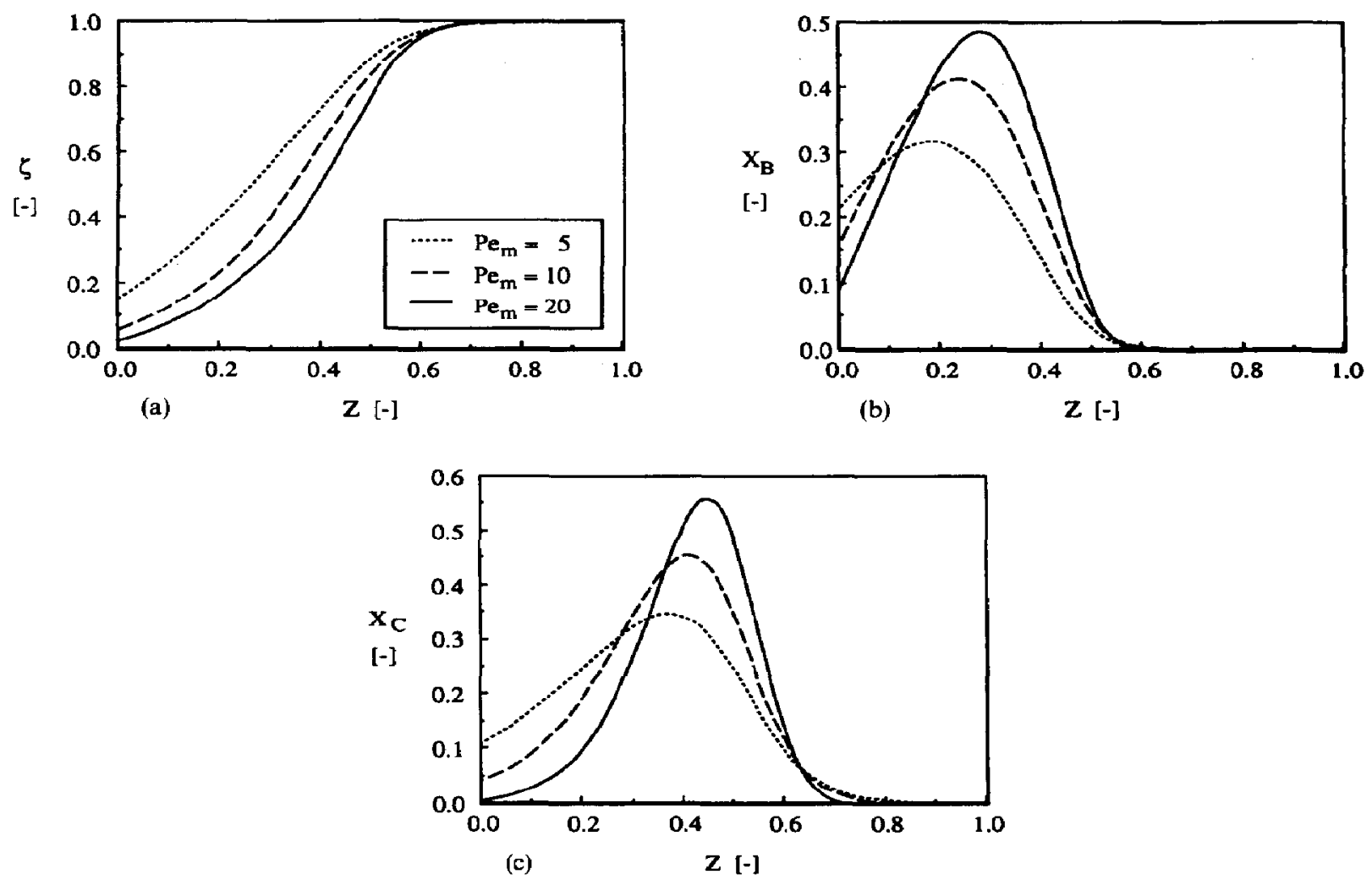

Fig. 15. Influence of $P e_{m}$ on the calculated conversion profiles (a) and concentration profiles of B (b) and C (c). Parameter values are $D a=6.9, \alpha_{\mathrm{P}}=2.0, \gamma=6.38, \eta=0.4, T_{\mathrm{o}}=50^{\circ} \mathrm{C}, P=0.5 \mathrm{MPa}, S t^{\prime}=705$ and $P e_{\mathrm{h}}=2.5$.
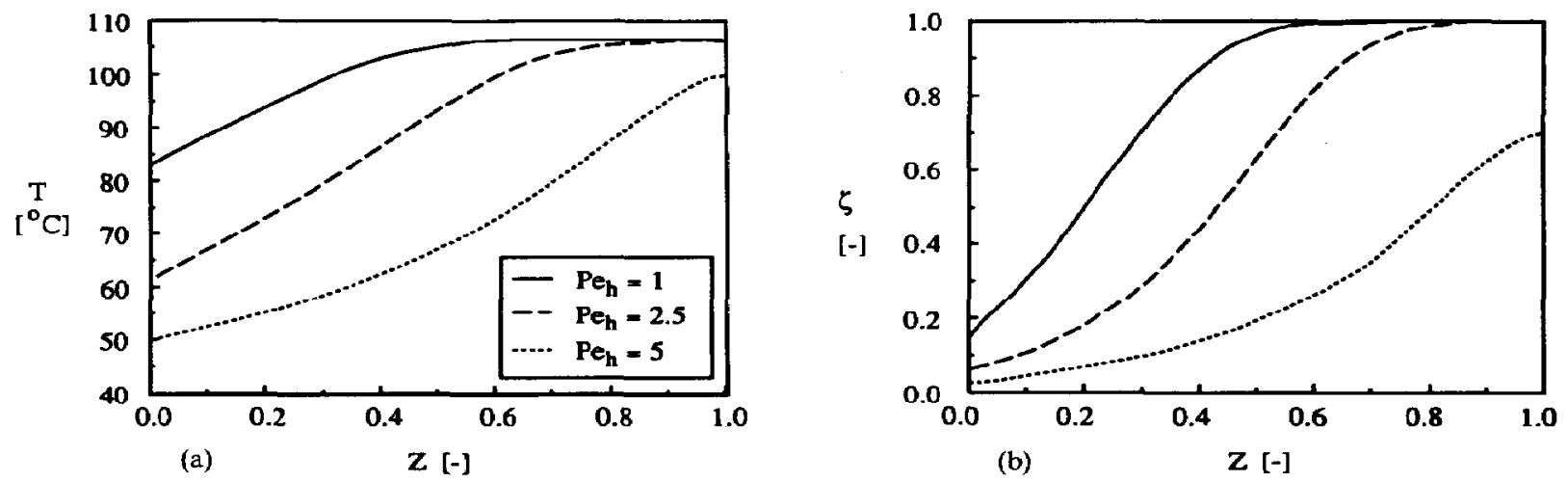

Fig. 16. Influence of $P e_{\mathrm{h}}$ on the calculated temperature (a) and conversion (b) profiles in the catalyst bed. Model parameters are $D a=6.9, P e_{m}=7.5, T_{0}=50^{\circ} \mathrm{C}, \alpha_{\mathrm{p}}=2.0, \gamma=6.38, \eta=0.35$ and $S t^{\prime}=705$.

its simplicity and because it can be solved on practically any computer with standard mathematical techniques. It is therefore very valuable in gaining an understanding of the basic behaviour of the reactor and it will definitely be very useful for reactors in which axial mixing and axial heat conduction are restricted, for instance in a cocurrent downflow trickle bed reactor. We will compare only the dispersion model with our experimental results. To obtain a best fit between model and experiment the parameters varied are $\eta$, a measure for the catalyst activity, and the Peclet numbers for heat and mass transfer, $P e_{m}$ and $P e_{\mathbf{h}}$.

9.1.2. Influence of gas and liquid flow rate. The parameters $P e_{m}$ and $P e_{\mathrm{h}}$ in the dispersion model are assumed to be constant over the length of the catalyst bed. For a packed bubble column reactor we found 
that $P e_{m}$ could best be correlated with the superficial velocities of the gas and the liquid phase in the reactor as follows:

$$
P e_{\mathrm{m}}=0.065\left(\frac{L}{d_{\mathrm{p}}}\right) U_{\mathrm{L}}^{0.31} U_{\mathrm{G}}^{-0.18}
$$

This equation has been derived under isothermal conditions of no evaporation. However, in the reactor the flow rates vary significantly due to the evaporation. These variations will definitely have an influence, and thus $P e_{m}$ will not be constant over the reactor length. The same will hold for $P e_{h}$. As the liquid flow rate decreases and the gas flow rate increases the above correlation predicts that $P e_{m}$ will decrease in the direction of flow through the bed. This variation in the gas and liquid flow rates will also cause a hold-up profile in the reactor, but as long as the catalyst surface remains fully wetted this has no consequences. The temperature profile over the reactor will surely influence the values of $P e_{\mathrm{m}}$ and $P e_{\mathrm{h}}$. The temperature gradients are therefore another reason why the assumption of constant values for $P e_{m}$ and $P e_{\mathrm{h}}$ is too simple.

9.1.3. Influence of the evaporation. The influence of the evaporation rate itself on $P e_{m}$ and $P e_{h}$ could not be accounted for as it is unknown. Especially in the area where the evaporation rate is high this may well cause an extra turhulence in the reactor, thereby increasing the axial dispersion of mass and heat.

9.1.4. Catalyst deactivation. Catalyst deactivation is a serious problem in the industrial operation of catalytic reactors. The parameter governing the catalyst activity in our model is $\eta$. Under conditions of deactivation it is very unlikely that the rate of deactivation is the same throughout the catalyst bed. Thus, an activity profile may develop which may seriously influence the reactor performance. The exist- ence and actual form of such a profile can generally only be guessed. The value of $\eta$ that results in the best fit of the model to the experimental data is only a mean value of $\eta$ over the catalyst bed. We will show that it is a good indication of the catalyst activity by comparing the values of $\boldsymbol{\eta}$ calculated for several stages of deactivation.

\subsection{Comparison between model and experiments}

A complete list of all experimental conditions and results is given in Part $I$, Table 1.

The calculated temperature and conversion profiles and the experimentally measured temperature and conversion data for experiments $27 \mathrm{~S}, 36,40$ and 14 are given in Figs 17, 18,19 and 20, respectively. From these figures we see that the experiment with a fresh catalyst, $27 \mathrm{~S}$, can be fitted with a good accuracy. The agreement between the other experiments and the model calculations is much less. This is probably due to the deactivation of the catalyst. Comparing the calculated profiles with the experimental data it is clear that the temperature and conversion increases in the first half of the reactor are faster than predicted; the opposite is true for the second half of the reactor. This can be caused by a decreasing catalyst activity in the direction of flow, which implies that the deactivation is faster in the second half of the reactor. This can be understood because the temperature level in the second half of the reactor is higher than in the first part of the reactor, resulting in a faster deactivation.

The values for $P e_{m}$ resulting in a best fit between model and experiment are generally much lower than the values estimated from eq. (50). For experiment 36 the value for $P e_{m}$ estimated with our correlation is 7.5 at the entrance and 6.0 at the exit of the catalyst bed. The best fit value for Fig. 18 is 2.5 . The variation in the gas and liquid flow rates cannot fully account for this difference. The higher temperature level in the reactor compared to the conditions under which the correlation was derived and the strong evaporation are probably two other causes for the increased mixing.



(b)

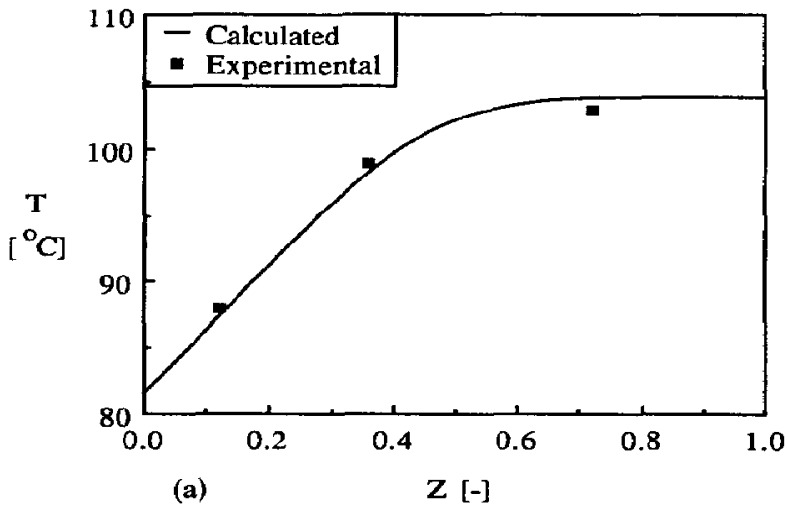

Fig. 17. Comparison between the temperature profile (a) and the conversion profile (b) calculated with the dispersion model and experimental data obtained in our miniplant. Experimental conditions are $\varphi_{\mathrm{L}}=10.6$ $\times 10^{-3} \mathrm{~m}^{3} / \mathrm{h}, \quad \varphi_{\mathrm{G}}=1.08 \mathrm{~N} \mathrm{~m}^{3} / \mathrm{h}, \quad T_{\mathrm{o}}=50^{\circ} \mathrm{C}, \quad X_{\mathrm{A}_{0}}=0.00873, \quad \Delta T_{\mathrm{ad}}=168^{\circ} \mathrm{C}, \quad P=0.49 \mathrm{MPa}, \quad L$ $=0.95 \mathrm{~m}$. Parameter values are $\mathrm{Da}=6.95, \alpha_{\mathrm{P}}=2.4, \gamma=5.38, \eta=0.365, P e_{\mathrm{m}}=5.0, P e_{\mathrm{h}}=0.9$ and $S t^{\prime}$ $=760$. 

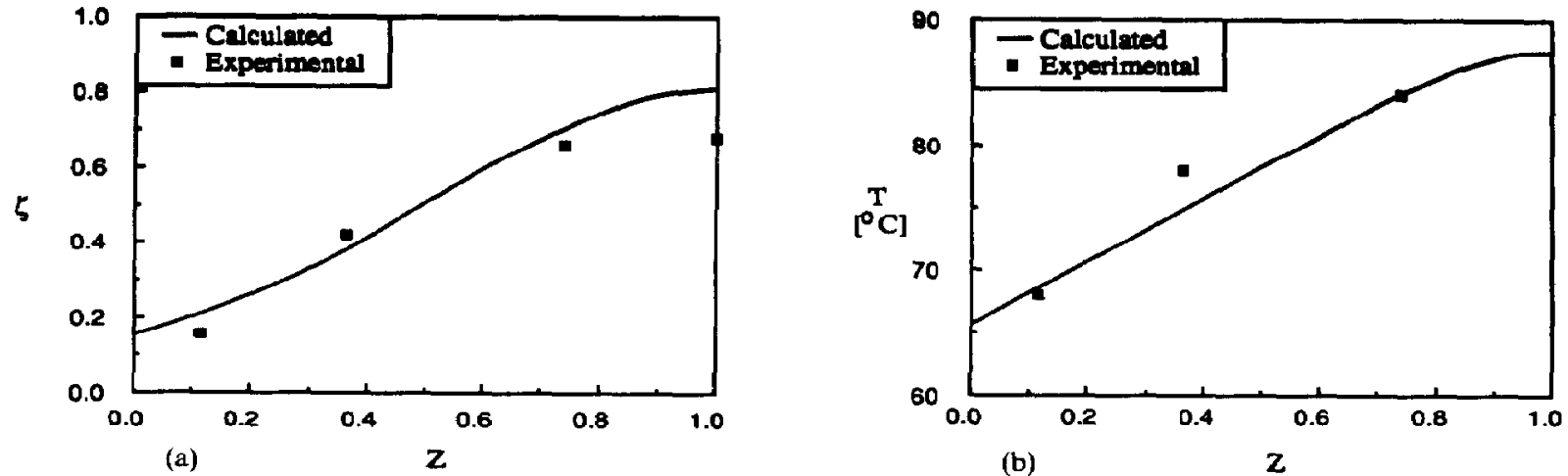

Fig. 18. The temperature (a) and conversion (b) profiles as calculated with the dispersion model and the experimental data for experiment 36. Experimental conditions are $\varphi_{\mathrm{L}}=7.5 \times 10^{-3} \mathrm{~m}^{3} / \mathrm{h}$, $\varphi_{\mathrm{G}}=1.42 \mathrm{~N} \mathrm{~m}^{3} / \mathrm{h}, T_{0}=60^{\circ} \mathrm{C}, X_{\mathrm{A} 0}=0.00873, \Delta T_{\text {ad }}=168^{\circ} \mathrm{C}, P=0.40 \mathrm{MPa}$ and $L=0.95 \mathrm{~m}$. Parameter values are $D a=9.6, \alpha_{\mathrm{p}}=4.5, \gamma=2.8, \eta=0.27, P e_{\mathrm{m}}=3.5, P e_{\mathrm{h}}=0.7$ and $S t^{\prime}=550$.
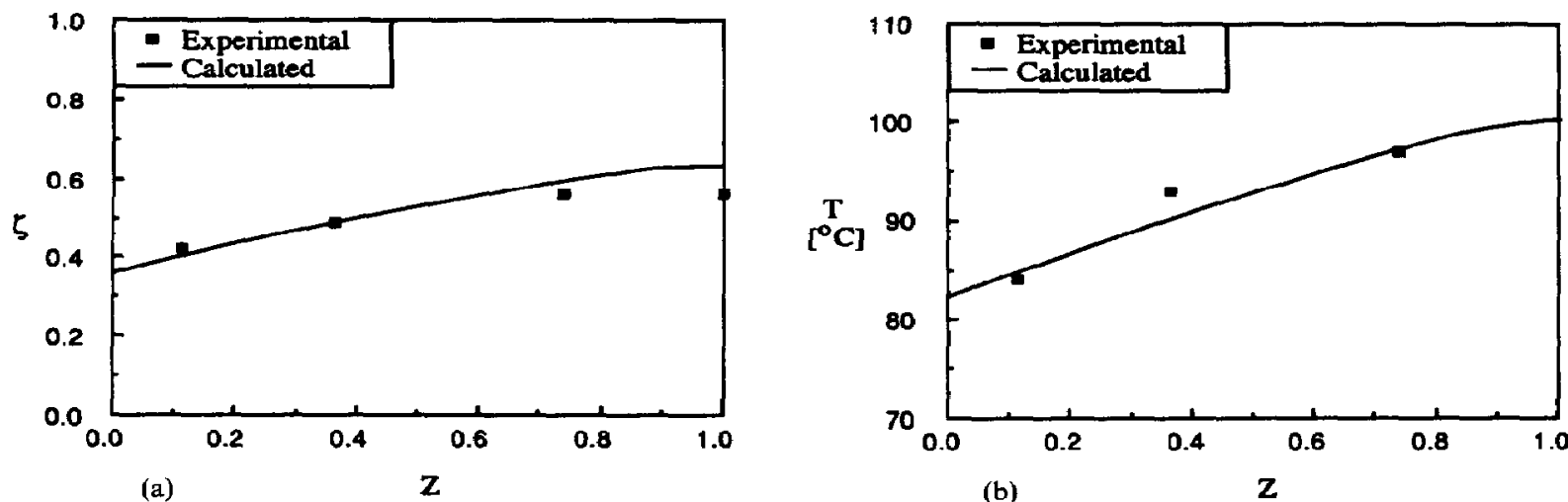

Fig. 19. The temperature (a) and conversion (b) profiles as calculated with the dispersion model and the experimental data for experiment 40. Experimental conditions are $\varphi_{\mathrm{L}}=7.5 \times 10^{-3} \mathrm{~m}^{3} / \mathrm{h}$, $\varphi_{\mathrm{G}}=0.35 \mathrm{~N} \mathrm{~m}^{3} / \mathrm{h}, T_{\mathrm{O}}=60^{\circ} \mathrm{C}, X_{\mathrm{A} 0}=0.00873, \Delta T_{\mathrm{ad}}=168^{\circ} \mathrm{C}, P=0.40 \mathrm{MPa}$ and $L=0.95 \mathrm{~m}$. Parameter values are $D a=9.5, \alpha_{\mathrm{p}}=1.1, \gamma=11.2, \eta=0.105, P e_{\mathrm{m}}=0.7, P e_{\mathrm{h}}=0.65$ and $S t^{\prime}=800$.

We would expect the values of $P e_{\mathrm{h}}$ and $P e_{\mathrm{m}}$ to be approximately equal. However, the values for $P e_{\mathrm{h}}$ that we find are much lower than the values for $P e_{m}$. The axial dispersion of heat is apparently larger than the axial dispersion of mass. This is caused by the extra contribution to axial heat dispersion by the liquid flowing downward in the annulus between the catalyst bed and the outer cylinder of the reactor.

\subsection{Deactivation}

In Part I we discussed two sets of experiments to investigate the catalyst deactivation. We could only discuss the deactivation in terms of decreasing conversion. With our models we now have a parameter that gives us a quantitative figure for the extent of deactivation, $\eta$. In Tables 1 and 2 we add the calculated values for $\eta$ to the experimental results of Tables 5 and 6 of Part I. Table 1 refers to a long duration experiment during which the operating conditions were held constant. Table 2 refers to experiments $27 \mathrm{~S} 45 \mathrm{~S}$ which were done consecutively without stopping the reaction in between experiments. It is clear that $\eta$ decreases with time on stream and with increasing deactivation. We conclude that $\eta$ is a good measure for the average catalyst activity.

\section{REACTOR DESIGN AND OPERATION}

With our models we have studied the behaviour of a reactor with an evaporating solvent. We have identified the main operating variables as the reactor pressure, the hydrogen supply ratio and the feed temperature. We have studied how changes in these variables influence the reactor performance. Using this knowledge we will now discuss some points of interest regarding the design and operation of a packed bubble column with an evaporating solvent.

\subsection{Design considerations}

It is a well known phenomenon that the presence of axial mass and heat dispersion strongly decreases the yield to intermediate products. This has been shown clearly in Fig. 15(a) and (b). Axial mass and heat dispersion should therefore be suppressed as much as 

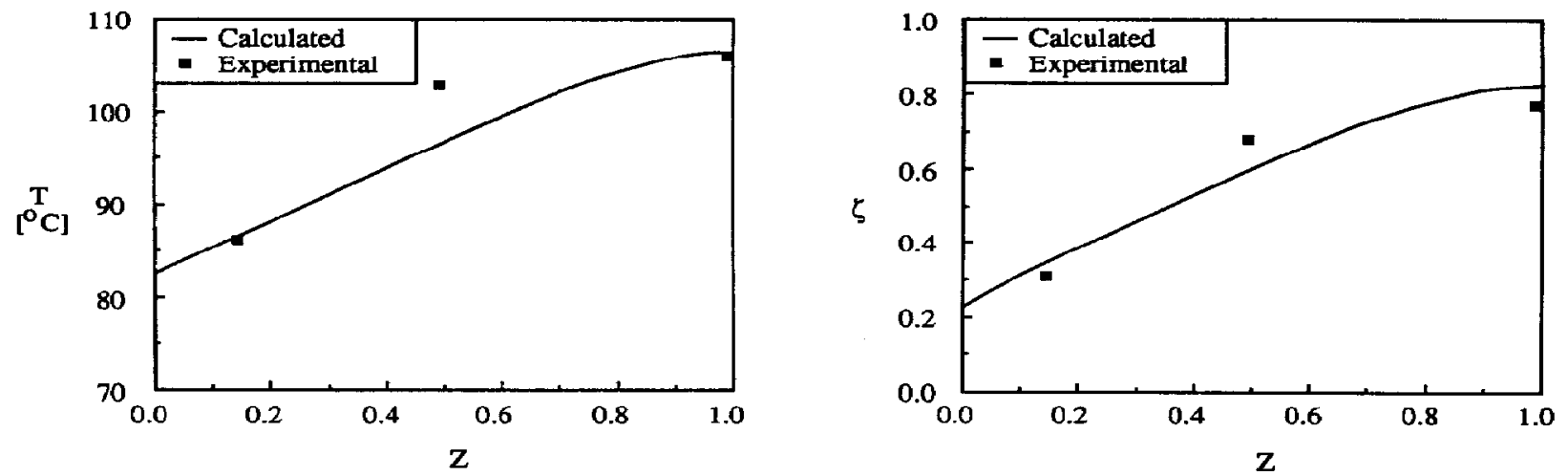

Fig. 20. The temperature (a) and conversion (b) profiles as calculated with the dispersion model and the experimental data for experiment 14. Experimental conditions are $\varphi_{\mathrm{L}}=6.8 \times 10^{-3} \mathrm{~m}^{3} / \mathrm{h}, \varphi_{\mathrm{G}}$ $=0.72 \mathrm{~N} \mathrm{~m}^{3} / \mathrm{h}, T_{0}=49.5^{\circ} \mathrm{C}, X_{\mathrm{Ao}}=0.00873, \Delta T_{\mathrm{ad}}=168^{\circ} \mathrm{C}, P=0.60 \mathrm{MPa}$ and $L=0.71 \mathrm{~m}$. Parameter values are $D a=7.6, \alpha_{\mathrm{p}}=2.5, \gamma=5.1, \eta=0.14, P e_{\mathrm{m}}=2.0, P e_{\mathrm{h}}=0.6$ and $S t^{\prime}=800$.

possible. To this end a long and small diameter reactor is more suitable than a short and wide reactor.

When airning at the production of intermediates in complex reactions the trick of the trade is to operate the reactor in such a way that the maximum in the concentration profile for the desired intermediate occurs at the exit of the catalyst bed. Any change in the operating conditions will change the position of this maximum and should be accompanied by changes in other operating conditions in order to compensate for the shifting position of the maximum. Controlling the yield of the desired product therefore will be very difficult. An easy way to control the yield to compon-

Table 1. Decrease in catalyst activity during continuous opcration of the reactor at constant operating conditions

\begin{tabular}{|c|c|c|c|c|c|c|c|}
\hline \multirow{2}{*}{$\begin{array}{c}\text { Time } \\
\text { (h) }\end{array}$} & \multirow{2}{*}{$\begin{array}{c}T_{1} \\
\left({ }^{\circ} \mathrm{C}\right)\end{array}$} & \multirow{2}{*}{$\begin{array}{c}T_{2} \\
\left({ }^{\circ} \mathrm{C}\right)\end{array}$} & \multirow{2}{*}{$\begin{array}{c}T_{3} \\
\left({ }^{\circ} \mathrm{C}\right)\end{array}$} & \multirow[b]{2}{*}{$\zeta_{1}$} & \multirow[b]{2}{*}{$\zeta_{2}$} & \multirow[b]{2}{*}{$\zeta_{3}$} & $\eta_{t}$ \\
\hline & & & & & & & $\eta_{t}=10$ \\
\hline 10 & 78 & 89 & 93 & 0.27 & 0.65 & 0.67 & 1.000 \\
\hline 20 & 78 & 89 & 93 & 0.27 & 0.63 & 0.64 & 0.987 \\
\hline 30 & 77 & 86 & 90 & 0.27 & 0.61 & 0.61 & 0.962 \\
\hline 40 & 77 & 85 & 90 & 0.27 & 0.58 & 0.58 & 0.936 \\
\hline 50 & 76 & 85 & 88 & 0.27 & 0.55 & 0.55 & 0.910 \\
\hline
\end{tabular}

Note: catalyst activity at $t=10 \mathrm{~h}$ is set at 1 . ent $i$ in a long reactor is by setting the hydrogen supply ratio $\alpha_{i}$ close to 1 so that the reaction stops once the highest concentration has been reached. In Fig. 6 we showed that in this case practically all hydrogen will be consumed causing the reaction to stop so that the liquid phase composition remains constant further on in the reactor. We do not care for the location of the maximum concentration as long as this maximum is reached before the reactor exit.

In an evaporating system the pressure is one of the most important operating variables and much attention should be paid to the pressure control system on the reactor. Especially when a hydrogen supply ratio $x_{p}<1$ is chosen and therefore practically all hydrogen is consumed, the gas flow leaving the reactor will become very small and controlling the pressure may prove difficult. In this case the addition of a small amount of an inert non-reacting component to the gas feed stream can be used in order to increase the gas flow out of the reactor. This results in a decrease in the hydrogen partial pressure in the reactor and also in a temperature decrease because of the increased evaporation of the solvent.

The use of low values of $\alpha_{i}$, preferably around $\alpha_{i}$ $=1$, also favourably influences the investment and operating costs. The small excess of hydrogen can

Table 2. Decrease in catalyst activity during continuous operation with varying operating conditions

\begin{tabular}{ccccccccc}
\hline Code & $\begin{array}{c}T_{1} \\
\left.{ }^{\circ} \mathrm{C}\right)\end{array}$ & $\begin{array}{c}T_{2} \\
\left.{ }^{\circ} \mathrm{C}\right)\end{array}$ & $\begin{array}{c}T_{3} \\
\left({ }^{\circ} \mathrm{C}\right)\end{array}$ & $\zeta_{1}$ & $\zeta_{2}$ & $\zeta_{3}$ & $\zeta_{L}$ & $\frac{\eta_{275}}{}$ \\
\hline $27 \mathrm{~S}$ & 88 & 101 & 103 & 0.42 & 0.79 & 0.85 & 0.99 & 1.00 \\
$33 S$ & 80 & 99 & 100 & 0.18 & 0.47 & 0.68 & 0.68 & 0.73 \\
$37 \mathrm{~S}$ & 79 & 93 & 99 & 0.19 & 0.46 & 0.65 & 0.67 & 0.71 \\
$45 \mathrm{~S}$ & 77 & 85 & 92 & 0.11 & 0.32 & 0.47 & 0.47 & 0.63 \\
\hline
\end{tabular}

Note: catalyst activity for experiment $27 \mathrm{~S}$ is set at 1 . Experiment $33 \mathrm{~S}$ at approximately $28 \mathrm{~h}$, experiment $37 \mathrm{~S}$ at approximately $41 \mathrm{~h}$ and experiment $45 \mathrm{~S}$ at approximately $58 \mathrm{~h}$ after start-up. 
now be purged directly so that an expensive recirculation system with extra condensors and a hydrogen compressor can be avoided. As the solvent evaporated always has to be recovered, probably by condensation outside the reactor, we have to transport the vapours to the condensors. This can be done with a small stream of inert gases and in this case also a undesired decrease in reactor pressure by a too strong cooling in the condensors can be avoided. As a favourable side effect this means that quality demands for the hydrogen generation or supply are not too high.

\subsection{Reactor operation}

Suppose we operate a reactor in which a reaction $\mathbf{A} \rightarrow \mathbf{B} \rightarrow \mathbf{C} \rightarrow \mathbf{P}$ takes place and suppose that the kinetics for this reaction are the same as used in our model illustrations. We wish to produce $C$. The values for the operating parameters are $D a=4.3, \alpha_{c}=1.0, \gamma$ $=15.9, T_{0}=55^{\circ} \mathrm{C}, P=0.4 \mathrm{MPa}$ and $\eta=0.35$, which results in a yield of $C$ at the reactor exit of 0.62 . We will now discuss how to operate the reactor in several situations that may arise in industrial practise and how this will influence the yield obtained.

10.2.1. Deactivation of the catalyst. Deactivation of the catalyst results in lower reaction rates and consequently in a decreasing yield. There are two options to compensate for this deactivation: increasing the reactor pressure and increasing the feed temperature. Both actions will increase the average reactor temperature, thus compensating for the lower catalyst activity. Increasing the feed temperature will mainly increase the temperature near the entrance of the bed as the final temperature in the reactor is determined by the reactor pressure. Increasing the pressure will mainly increase the temperature level in the last part of the reactor [compare Figs 8(a) and 9(a)]. The differential selectivity $\sigma_{c}^{\prime}$ given in eq. (44) is a measure of the yield; it mainly depends on the temperature, decreasing with increasing temperature. For a high yield of $C$ we are interested in the last part of the reactor where $C$ is formed. A temperature increase in this part of the reactor will be more harmful for the yield than a temperature increase in the first part of the reactor. Increasing the feed temperature is therefore the best way to compensate for a deactivating catalyst.

For a $10 \%$ deactivation the feed temperature has to be increased from 55 to $65^{\circ} \mathrm{C}$.

10.2.2. Increasing the production of $C$. Suppose we want to increase the production rate of $\mathrm{C}$ by $50 \%$. This means that we have to increase the capacity of the reactor. Because the reactions are effectively zero order in reactant concentration, increasing the residence time or the reactant concentration will not be effective. The reactor capacity can only be increased by increasing the reaction rate and thus by increasing the reactor temperature. This can be achieved by increasing $T_{0}$ or by increasing the reactor pressure. Based on the same arguments as before, increasing $T_{0}$ is preferred but this may not prove to be sufficient for such a drastic increase in the production rate. Therefore, a combination of both options should be considered here. However, the result of the temperature increase will again be a lower yield of $C$.

For the data given an increase in the feed temperature from 55 to $70^{\circ} \mathrm{C}$ and of the reactor pressure from 0.4 to $0.5 \mathrm{MPa}$ results in the desired production increase. Regretfully the yield decreases from 0.62 to 0.58 . If the reactor were to have an overdesign in its length the desired production increase could have been achieved without loss in yield.

10.2.3. Decreasing the production of $C$. Because the reactor is operated with $\alpha_{C}=1$ a production decrease of, say, $20 \%$ is easy to achieve and can be obtained by simply decreasing the liquid and gas feed flow rates by $20 \%$. The resulting increase in the residence time of the liquid phase in the reactor has no influence on the yield because the reaction stops due to a lack of hydrogen. Under these new conditions the reactor is strongly overdesigned and we can consider decreasing the reactor pressure in order to increase the yield. Decreasing the reactor pressure from 0.4 to $0.3 \mathrm{MPa}$ results in an increase of the yield from 0.62 to 0.67 .

\section{CLOSING REMARKS}

In the previous sections we presented two models to describe a cocurrent three-phase packed bed bubble column reactor with an evaporating solvent. From a comparison between the dispersion model and one of our experiments we concluded that the agreement between the dispersion model and the experiment was good. However, there are several phenomena that may influence the validity of our assumptions.

We can imagine that in a packed bubble column reactor the gas hold-up $\varepsilon_{\mathrm{G}}$ increases due to the evaporation and that simultaneously the liquid hold-up $\varepsilon_{\mathrm{L}}$ decreases. This does not influence our basic equations in both models, because they are based on the assumption that in the reactor the catalyst is fully wetted. We have to realize that as soon as the catalyst wetting is no longer complete, the available catalyst surface area decreases and in that case our models are no longer valid.

We showed that due to the evaporation the gas flow rate increases and the liquid flow rate decreases. This will certainly influence the magnitude of the axial mass and heat dispersion coefficients because we found these to be dependent on both the gas and liquid flow rates in the reactor. Therefore $P e_{m}$ and $P e_{h}$ may not be constant over the reactor length. The temperature gradient in the catalyst bed is another reason why the assumption of constant values for $P \boldsymbol{e}_{\mathrm{m}}$ and $P e_{\mathrm{h}}$ is definitely too simple.

Catalyst deactivation is a serious problem in the operation of catalytic reactors. A loss in the catalyst activity can be caused by poisoning or by the formation of a coke layer on the catalyst surface. The rate of deactivation will, in the case of coking, depend on the 
temperature level and may depend on the presence of certain reaction products. Under conditions of deactivation it is therefore very unlikely that the rate of deactivation is the same throughout the catalyst bed so that an activity profile may develop. This will certainly influence the reactor performance and under these conditions the models we presented are no longer valid. This is an argument to use an overdesigned slender reactor with $\alpha_{i} \approx 1$.

\section{CONCLUSIONS}

Two models were developed to describe a cocurrent three-phase packed bed bubble column reactor in which an evaporating solvent is used to absorb and remove most of the reaction heat. These models are a plug flow model and a dispersion model.

The influence of the main operating parameters was discussed. These are the hydrogen supply ratio $\alpha$, the reactor pressure and the feed temperature. Increasing the hydrogen supply ratio $\alpha$ results in an increase of the evaporation rate and a decrease of the temperature level. This need not directly result in a lower conversion, because the hydrogen partial pressure is raised. Increasing the feed temperature results in a higher reactor temperature level. The reactor pressure determines the boiling point of the solvent and is the most influential parameter. Increasing the pressure raises the boiling point and consequently the temperature level. For the hypothetical series of consecutive reactions an increase in the reactor temperature results in lower selectivities to the intermediates.

The dispersion model could well describe our experimental results. For our packed bubble column reactor the plug flow model is inadequate. We are confident that this model will be valuable for reactors in which mass and heat dispersion is hardly present, i.e. in cocurrent downflow trickle flow reactors.

We discussed that when aiming at the production of intermediates in complex reactions it will be difficult to operate the reactor in such a way that the maximum yield to the desired intermediate is reached at the reactor exit. Setting the hydrogen supply ratio $\alpha_{i}$ of the desired intermediate close to 1 eliminates this problem because the reaction stops once the highest concentration of component $i$ has been reached and all the hydrogen has been consumed. The location of this maximum is then not important as long as the maximum is reached before the reactor exit.

We discussed how to operate the reactor in several situations that may arise in industrial practice and how this will influence the yield. We showed that any change in the operating conditions that increases the temperature level will decrease the yield. Increasing the feed temperature will mainly increase the temperature level near the reactor entrance, increasing the pressure will mainly increase the temperature level near the exit. Because the desired intermediate is formed in the last part of the catalyst bed an increase in the temperature level in that part of the reactor must be avoided if possible. Therefore increasing the

feed temperature is the preferred way to increase the reactor capacity, i.e. for compensating for catalyst deactivation.

Because the processes that determine the behaviour and performance of a reactor in which evaporation of the solvent occurs are very complex the operation of an industrial reactor without the help of a computer model and reliable kinetic data is hardly possible. The results and models we presented in this paper may serve as a basis for understanding the behaviour of reactors with an evaporating solvent. Each application should be studied separately, substituting the relevant kinetic and physical data into the models.

Acknowledgements- - These investigations were supported by the Netherlands Foundation for Chemical Research with financial aid from the Netherlands Technology Foundation. The authors wish to thank Dr. F. P. H. van Beckum for his suggestions on the numerical solution of the dispersion model.

\section{NOTATION}

$a_{\mathrm{G}}$

$C_{i}$

$C_{\mathrm{p}}$

$C_{\mathrm{p}}$

$D_{\text {ax }}$

$D a$

$D a_{i}$

DANT

DNHAT

$\boldsymbol{E}_{i}$

$F_{i j}$

$h$

$\boldsymbol{H}_{\mathrm{ai}}$

$k_{G}$

$k_{i}$

$K_{i}$

L

$m_{\text {cat }}$

$M$

$M$

$n_{i}$

$P_{i}$

$P$

$P_{i}$

$P_{\mathrm{s}}$

$P e_{\mathrm{h}}$

$P e_{\mathrm{m}}$

$r_{\text {prod, } i}$ specific gas-liquid interfacial area, $\mathrm{m}^{-1}$ concentration of component $i, \mathrm{kmol} / \mathrm{m}^{3}$ specific heat, $\mathrm{kJ} / \mathrm{kg} \mathrm{K}$ dimensionless specific heat $=C_{\mathrm{p}} / C_{\mathrm{p} o}$ axial dispersion coefficient, $\mathrm{m}^{2} / \mathrm{s}$ Damköhler number, defined in eq. (32) Damköhler number at which the maximum yield for component $i$ is reached diaminonitrotoluene

dinitrohydroxylaminotoluene activation energy for reaction of component $i$ to component $i+1, \mathrm{~kJ} / \mathrm{mol}$

functions defined in eq. (22)

axial coordinate, $\mathrm{m}$

activation energy for adsorption of component $i, \mathrm{~kJ} / \mathrm{mol}$

mass transfer coefficient, $\mathrm{m} / \mathrm{s}$ reaction rate parameter for reaction of component $i$ to component $i+1$, $\mathrm{kmol} / \mathrm{m}^{3} \mathrm{~s}$

adsorption parameter for component $i$, $\mathrm{m}^{3} / \mathbf{k m o l}$

reactor length, $\mathrm{m}$

mass of catalyst in eq. (1), $\mathrm{kg}$ catalyst $/ \mathrm{m}^{3}$ molar mass, $\mathrm{kg} / \mathrm{kmol}$

dimensionless molar mass $=M / M_{0}$ number of moles of hydrogen needed for complete conversion of 1 mole of reactant $\mathrm{A}$ to component $i$

dimensionless pressure of component $i$, defined as $P_{i} / P_{S}$

total pressure, $\mathrm{N} / \mathrm{m}^{2}$

partial pressure of component $i, \mathrm{~N} / \mathrm{m}^{2}$ standard pressure

Peclet number for heat dispersion, defined in eq. (49)

Peclet number for mass dispersion, defined in eq. (48)

production rate of component $i, \mathrm{kmol} /$ $\mathbf{m}^{3} \mathrm{~s}$ 


\begin{tabular}{|c|c|c|}
\hline$r_{i}$ & $\begin{array}{l}\text { reaction rate for reaction of } i \rightarrow i+1 \text {, } \\
\mathbf{k m o l} / \mathrm{m}^{3} \mathrm{~s}\end{array}$ & $\theta$ \\
\hline $\boldsymbol{R}_{\mathrm{i}}$ & dimensionless reaction rate: $r_{i} / \rho_{\mathrm{b}} k_{1, \mathrm{~s}}$ & $\Theta$ \\
\hline $\boldsymbol{R}_{\text {prod, } i}$ & $\begin{array}{l}\text { dimensionless production rate of com- } \\
\text { ponent } i, r_{\text {prod, } i} / \rho_{b} k_{1, s}\end{array}$ & $\kappa_{i}$ \\
\hline $\boldsymbol{R}$ & gas constant, $\mathbf{J} / \mathbf{k m o l ~ K}$ & $\lambda_{i}$ \\
\hline$S t^{\prime}$ & $\begin{array}{l}\text { modified Stanton number (also called } \\
\text { NTU), defined in eq. ( } 47 \text { ) }\end{array}$ & $\lambda_{\text {eff }}$ \\
\hline$T$ & temperature, $\mathbf{K}$ & \\
\hline$T_{\mathrm{S}}$ & standard temperature & $\rho$ \\
\hline TAT & 2,4,6-triaminotoluene & $\rho_{\text {eat }}$ \\
\hline TNT & 2,4,6-trinitrotoluene & \\
\hline$x_{i}$ & $\begin{array}{l}\text { mole fraction of component } i \text { in the } \mathrm{li} \text { - } \\
\text { quid phase }\end{array}$ & $\rho_{\mathbf{L}}$ \\
\hline $\boldsymbol{X}_{i}$ & $\begin{array}{l}\text { dimensionless mole fraction of compon- } \\
\text { ent } i: x_{i} / x_{\mathrm{A}, 0}\end{array}$ & $\phi$ \\
\hline$y_{i}$ & $\begin{array}{l}\text { mole fraction of component } i \text { in the gas } \\
\text { phase }\end{array}$ & $\phi_{\mathrm{tr}}^{i}$ \\
\hline$Z$ & dimensionless axial coordinate $=h / L$ & \\
\hline$\alpha$ & hydrogen supply ratio: ratio of the num- & \\
\hline & $\begin{array}{l}\text { actor per unit of time to the number of } \\
\text { moles of TNT fed to the reactor per unit }\end{array}$ & $\begin{array}{l}\Psi \\
\varphi \\
\Psi\end{array}$ \\
\hline & of time, defined in eq. (33) & \\
\hline$\alpha_{i}$ & $\begin{array}{l}\text { hydrogen supply ratio based on compon- } \\
\text { ent } i \text {, defined in eq. (34) }\end{array}$ & \\
\hline & ities of the & \\
\hline
\end{tabular}

dimensionless temperature: $-\left(E_{1}(1-\right.$ $\left.T / T_{\mathrm{S}}\right) / R T_{\mathrm{s}}$ )

function defined as $\exp (\theta /(1+\Psi \theta))$

ratio of adsorption constants, defined in eq. (31)

ratio of reaction rate constants, defined in eq. (31)

effective axial thermal conductivity, $\mathbf{W} / \mathbf{m}^{2} \mathbf{K}$

density, $\mathrm{kg} / \mathrm{m}^{3}$

specific catalyst mass, $\mathrm{kg}$ catalyst $/ \mathrm{m}^{3}$ reactor

dimensionless density of the liquid phase: $\rho_{\mathrm{L}} / \rho_{\mathrm{LO}}$

molar flow rate per unit of cross-sectional area of the reactor, $\mathrm{kmol} / \mathrm{m}^{2} \mathrm{~s}$

number of moles of component $i$ transferred from the liquid to the gas phase per $\mathrm{m}^{3}$ reactor volume per unit of time, $\mathrm{kmol} / \mathrm{m}^{3} \mathrm{~s}$

dimensionless flow: $\phi / \phi_{0}$

flow rate, $\mathrm{m}^{3} / \mathrm{h}$

dimensionless parameter: $R T_{\mathrm{S}} / E_{1}$ ratio of activation temperature for reaction for component $i$ to the activation temperature for reaction for component $1: E_{i} / E_{1}$

liquid phase in the feed, defined in eq. (36) molar ratio of methanol to hydrogen in the feed, defined in eq. (35)

activity coefficient for component $i$ in the liquid phase

$\delta_{i} \quad$ ratio of activation temperature of adsorption for component $i$ to the activation temperature for reaction 1: $-H_{i} / E_{1}$

$\Delta E_{i}$

$\Delta H_{\mathrm{ev}}$

$\Delta H_{\mathrm{ri}}$ activation energy for reaction $i, \mathrm{~J} / \mathbf{k m o l}$ enthalpy of evaporation, $\mathrm{kJ} / \mathrm{mol}$ reaction enthalpy, $\mathrm{kJ} / \mathrm{mol}$ of component $i$ converted

$\Delta H_{i} \quad$ activation energy for adsorption of component $i, \mathrm{~J} / \mathrm{kmol}$

$\Delta T_{\mathrm{ad}, i} \quad$ dimensionless adiabatic temperature rise for reaction $i$, defined in eq. (37)

$\Delta T_{\mathrm{ev}} \quad$ dimensionless heat effect of evaporation of component $i$, defined in eq. (38)

$\Delta T_{\text {mixer }}$ dimensionless adiabatic temperature decrease over the mixer

$E_{G} \quad$ hold-up of the gas phase, $\mathrm{m}^{3} \mathrm{gas} / \mathrm{m}^{3}$ reactor

$\zeta \quad$ conversion, defined as the ratio of the amount of hydrogen consumed over the maximum amount of hydrogen consumed: $\zeta=\frac{2 X_{\mathrm{B}}+6 X_{\mathrm{C}}+9 X_{\mathrm{P}}}{9 \sum X}$

$\eta \quad$ catalyst activity

$\eta_{0} \quad$ scaling factor based on the difference in available surface area between the slurry catalyst used for the kinetics experiments and the shell catalyst used in the miniplant

$\eta_{i} \quad$ yield to product $i$

\section{Subscripts and superscripts \\ ax in axial direction \\ b referring to catalyst bed \\ ev evaporation \\ G gas phase \\ H hydrogen \\ L liquid phase \\ L at reactor exit \\ 0 feed conditions \\ R reactor conditions \\ S referring to standard conditions \\ sol solvent \\ W water}

\section{REFERENCES}

Carnahan B., Luther H. A. and Wilkes, J. O., 1969, Applied Numerical Methods. John Wiley, New York.

Janssen H. J., Vos, H. J. and Westerterp, K. R., 1987, Katalytisch hydrogeneren in een doorstroomde geroerde tankreactor, $\mathrm{I}^{2}$. Procestechnologie 3, 23-28.

Jenson, V. G. and Jeffreys, G. V., 1977, Mathematical Methods in Chemical Engineering, 2nd Edn. Academic Press, London.

Preis, W. H., Flannery, B. P., Tuekolsky, S. A. and Vetterling, W. T., 1987, Numerical Recipes. Cambridge University Press.

van Gelder, K. B., 1988, A packed bubble column reactor; use of an evaporating solvent. Ph.D. Thesis, University Twente.

van Gelder, K. B. and Westerterp, K. R., 1990, Residence time distribution and holdup in a cocurrent upflow packed bed reactor at elevated pressure and low Reynolds numbers. Chem. Engng Technol. 13, 27-40.

van Gelder, K. B., Damhof, J. K., Kroijenga, P. J. and Westerterp, K. R., 1990, Three-phase packed bed reactor with an evaporating solvent-I. Experimental: the hydro- 
genation of 2,4,6-trinitrotoluene in methanol. Chem. Engng Sci. 45, 3159-3170.

Westerterp, K. R. and Crombeen, P. R. J. J., 1983, Thermal behaviour of agitated gas-liquid reactors with $a$ vaporising solvent/air oxidation of hydrocarbons. Chem. Engng Sci. 38, 1331-1340.

Westerterp, K. R., van Swaaij, W. P. M. and Beenackers, A. A. C. M., 1984, Chemical Reactor Design and Operation. John Wiley, New York.

\section{APPENDIX A: PHYSICAL AND CHEMICAL DATA}

In this section we list all physical and chemical data that were used in the model simulations.

Kinetic parameters:

$$
\begin{array}{rlrl}
k_{1 \infty} & =1.94 \times 10^{6} \mathrm{kmol} / \mathrm{kg} \text { catalyst s } & E_{1} / R=-5410 \mathrm{~K} \\
k_{2 \infty}=256.0 \times 10^{6} \mathrm{kmol} / \mathrm{kg} \text { catalyst s } & E_{2} / R=-7200 \mathrm{~K} \\
k_{3 \infty}=160.0 \times 10^{6} \mathrm{kmol} / \mathrm{kg} \text { catalyst s } & E_{3} / R=-7020 \mathrm{~K} \\
K_{1 \infty}=19.2 \times 10^{-12} \mathrm{~m}^{3} / \mathrm{kmol} & H_{\mathrm{a} 1} / R=9100 \mathrm{~K} \\
K_{2 \infty}=124 \times 10^{-9} \mathrm{~m}^{3} / \mathrm{kmol} & H_{\mathrm{a} 2} / R=5590 \mathrm{~K} \\
K_{3 \infty}=215 \times 10^{-6} \mathrm{~m}^{3} / \mathrm{kmol} & H_{\mathrm{a} 3} / R=1915 \mathrm{~K} \\
K_{\mathrm{H} \infty}=0.1 \mathrm{~m}^{3} / \mathrm{kmol} & H_{\mathrm{aH}} / R=2000 \mathrm{~K} .
\end{array}
$$

Enthalpies of rcaction and evaporation:

$$
\begin{aligned}
\Delta H_{\mathrm{r} 1} & =413 \mathrm{~kJ} / \mathrm{mol} \\
\Delta H_{\mathrm{r} 2} & =825 \mathrm{~kJ} / \mathrm{mol} \\
\Delta H_{\mathrm{r} 3} & =614 \mathrm{~kJ} / \mathrm{mol} \\
\Delta H_{\mathrm{ev}, \text { Methanol }} & =32.5 \mathrm{~kJ} / \mathrm{mol} \\
\Delta H_{\mathrm{ev}, \text { water }} & =44.0 \mathrm{~kJ} / \mathrm{mol} .
\end{aligned}
$$

Specific heat of the components:

$$
\begin{aligned}
& C_{\text {p. } \text { Hz }_{2}} \text { (gas) }=14.5 \mathrm{~kJ} / \mathrm{kg} \mathrm{K} \\
& C_{\mathrm{p.MeOH}}(\text { gas) }=1.55 \mathrm{~kJ} / \mathrm{kg} \mathrm{K} \\
& C_{\text {p.MeOH }}(\mathrm{liq})=3.00 \mathrm{~kJ} / \mathrm{kg} \mathrm{K} \\
& C_{\text {p. } \mathrm{H}_{2} \mathrm{O}}(\mathrm{gas})=1.90 \mathrm{~kJ} / \mathrm{kg} \mathrm{K} \\
& C_{\mathrm{p}, \mathrm{H}_{2} \mathrm{O}}(\mathrm{liq})=4.18 \mathrm{~kJ} / \mathrm{kg} \mathrm{K} \text {. }
\end{aligned}
$$

Vapour pressure of the pure components $\left(\mathrm{N} / \mathrm{m}^{2}\right)$ :

$$
\begin{gathered}
\log _{10}\left(P_{\text {MCOH }}^{0}\right)=10.095-\frac{1521.23}{T-39.18} \\
\log _{10}\left(P_{\mathrm{H}_{2} \mathrm{O}}^{0}\right)=10.196-\frac{1730.63}{T \cdot 39.724} .
\end{gathered}
$$

The activity coefficients for the components in the liquid phase follow from the Margules equations:

$$
\begin{aligned}
\ln \left(\gamma_{\mathrm{H}_{2} \mathrm{O}}\right) & =\left[A_{12}-2\left(A_{21}-A_{12}\right) X_{\mathrm{H}_{2} \mathrm{O}}\right] X_{\mathrm{MeOH}}^{2} \\
\ln \left(\gamma_{\mathrm{MeOH}}\right) & =\left[A_{21}-2\left(A_{12}-A_{21}\right) X_{\mathrm{MeOH}}\right] X_{\mathrm{H}_{2} \mathrm{O}}^{2}
\end{aligned}
$$

in which

$$
\begin{aligned}
& A_{12}=0.8224 \\
& A_{21}=0.6000 .
\end{aligned}
$$

Density of the liquid phase $\left(\mathrm{kg} / \mathrm{m}^{3}\right)$ :

$$
\begin{aligned}
\rho_{\text {MeOH }}= & 292.8 \times \exp \left\{-\exp \left[\frac{2}{7} \ln \left(1-\frac{T}{512.55}\right)\right]\right. \\
& \times \ln (0.276)\}
\end{aligned}
$$

The standard conditions used are:

$$
\begin{aligned}
& T_{\mathrm{s}}=350 \mathrm{~K} \\
& P_{\mathrm{s}}=0.4 \mathrm{MPa} .
\end{aligned}
$$

Diverse parameters used in the models:

$$
\begin{aligned}
D_{\text {reactor }} & =0.12 \mathrm{~m} \\
k_{\mathrm{g}} & =0.1 \mathrm{~m} / \mathrm{s} \\
a_{\mathrm{g}} & =320 \mathrm{~m}^{2} / \mathrm{m}^{3} \\
\varepsilon_{\mathrm{G}} & =0.2 \\
M_{\mathrm{A}} & =227 \mathrm{~g} / \mathrm{mol} \\
\rho_{\mathrm{b}} & =780 \mathrm{~kg} \mathrm{catalyst} / \mathrm{m}^{3} \\
\eta_{\mathrm{O}} & =1.28 \times 10^{-3} .
\end{aligned}
$$

\section{APPENDIX B: NUMERICAL SOLUTION OF THE DISPERSION MODEL}

The second order boundary value equations from the dispersion model were solved using a discretization technique combined with a linearization of the non-linear terms and iteratively solving the resulting tri-diagonal system. Convergence of the iteration was accelerated using overrelaxation.

Backward discretization was used for the first order differentials because this method is more stable than central or forward discretization. Using backward discretization the first order derivative of the dependent variable $X$ at a position $j$ is written as:

$$
\frac{\mathrm{d} X}{\mathrm{~d} Z}=\frac{X_{j}-X_{j-1}}{\Delta Z}
$$

and the second order derivative as:

$$
\frac{\mathrm{d}^{2} X}{\mathrm{~d} Z^{2}}=\frac{X_{j-1}-2 X_{j}+X_{j+1}}{\Delta Z^{2}}
$$

If $N$ discretization points are used, including $Z=0$ and $Z$ $=1$, the resulting set of equations can be written as:

$$
\begin{aligned}
b_{1} X_{1}+c_{1} X_{2} & =d_{1} \\
a_{2} X_{1}+b_{2} X_{2}+c_{2} X_{3} & =d_{2} \\
a_{3} X_{2}+b_{3} X_{3}+c_{3} X_{4} & =d_{3} \\
\ldots \ldots \ldots & \\
a_{i} X_{i-1}+b_{i} X_{i}+c_{i} X_{i+1} & =d_{i} \\
\ldots \ldots \ldots & \\
a_{N-1} X_{N-2}+b_{N-1} X_{N-1}+c_{N-1} X_{N} & =d_{N-1} \\
a_{N} X_{N-1}+b_{N} X_{N} & =d_{N}
\end{aligned}
$$

or in matrix notation:

$$
[A][X]=[D] .
$$

The coefficient matrix $[A]$ is a so called tri-diagonal matrix and the system of linear equations (B3) in $X$ can be solved using a recursive technique [see Preis et al. (1987)]:

$$
\begin{aligned}
& X_{N}=\gamma_{N} \\
& X_{i}=\gamma_{i}-\frac{c_{i} X_{i+1}}{\beta_{i}}, i=N-1, N-2, \ldots, 1
\end{aligned}
$$

where the $\beta$ s and $\gamma$ s are determined from the recursion formulae:

$$
\begin{aligned}
& \beta_{1}=b_{1}, \quad \gamma_{1}=d_{1} / \beta_{1} \\
& \beta_{i}=b_{i}-\frac{a_{i} c_{i-1}}{\beta_{i-1}}, i=2,3, \ldots, N \\
& \gamma_{i}=\frac{d_{i}-a_{i} \gamma_{i-1}}{\beta_{i}}, i=2,3, \ldots, N .
\end{aligned}
$$

Using an initial estimate $[X]^{i}$ for the profile of the dependent variable a new profile $[X]^{i+1}$ can be estimated using eqs (B4) and (B5). This iteration is continued until a sufficient degree of accuracy is reached. 
Convergence of the iteration process can be greatly accelerated using over-relaxation. Now the new estimate $[A]^{i+1}$ is not used for the next iteration step, but the new estimate for the next iteration is calculated from $[A]^{\prime}$ as well as from $[A]^{i+1}$ using:

$$
[A]_{\text {new }}^{i+1}-[A]^{i}+R\left([A]^{i+1}-[A]^{i}\right)
$$

or

$$
[A]_{\text {new }}^{i+1}=R[A]^{i+1}+(1-R)[A]^{i} .
$$

In these equations $R$ is called the over-relaxation factor if $R>1$ and the under-relaxation factor if $R<1$. Generally the above process becomes instable for $R>2$ and there is an optimum value for $\boldsymbol{R}$ for which the acceleration reaches a maximum. This optimum has to be determined experimentally. For a hydrogen supply ratio $\alpha_{p}>1$ we used overrelaxation and we generally achieved good results with $R=1.45$. For a hydrogen supply ratio $\alpha_{\mathrm{p}}<1$ under-relaxation had to be used and good results were obtained with $R=0.6$.

In the set of eq. (B3) the terms that are non-linear in the dependent variable have to be linearized. These terms are the reaction terms and the mass transfer term which are not linear in the dimensionless temperature $\theta$. These non-linear terms are linearized as:

$$
R^{i+1}=R^{i}+\left(\theta^{i+1}-\theta^{i}\right) \frac{\delta R}{\delta \theta}
$$

and substituted in the difference equations. 